\title{
Long non-coding RNAs in brain tumors: roles and potential as therapeutic targets
}

\author{
Sung-Hyun Kim ${ }^{\dagger}$ Key-Hwan Lim, Sumin Yang and Jae-Yeol Joo* (i)
}

\begin{abstract}
Brain tumors are associated with adverse outcomes despite improvements in radiation therapy, chemotherapy, and photodynamic therapy. However, treatment approaches are evolving, and new biological phenomena are being explored to identify the appropriate treatment of brain tumors. Long non-coding RNAs (IncRNAs), a type of noncoding RNA longer than 200 nucleotides, regulate gene expression at the transcriptional, post-transcriptional, and epigenetic levels and are involved in a variety of biological functions. Recent studies on IncRNAs have revealed their aberrant expression in various cancers, with distinct expression patterns associated with their instrumental roles in cancer. Abnormal expression of IncRNAs has also been identified in brain tumors. Here, we review the potential roles of IncRNAs and their biological functions in the context of brain tumors. We also summarize the current understanding of the molecular mechanisms and signaling pathways related to IncRNAs that may guide clinical trials for brain tumor therapy.
\end{abstract}

Keywords: Brain disease, Genomics, Glioma, LncRNA, Neurodegenerative disease

\section{Background}

The occurrence of brain tumors is increasing worldwide and is more common among men than women [1] (Fig. 1). Glioma, a heterogeneous group of tumors, is one of the most common and major types of malignant brain tumors of the central nervous system. The World Health Organization has stated that according to cellular origin and based on histological subtypes and genetic features, gliomas can be subclassified into astrocytoma, oligoastrocytoma, oligodendroglioma, or glioblastoma. Moreover, each class of gliomas is categorized into grades I, II, III, and IV to assess the degree of malignancy, where grade $\mathrm{I}$ is the least malignant and grade IV is the most malignant $[2,3]$. In addition, brain tumors afflict a large number of individuals worldwide and are difficult to detect and treat. One problem associated with the treatment of

\footnotetext{
*Correspondence: joojy@kbri.re.kr

†Sung-Hyun Kim and Key-Hwan Lim have contributed equally to this work.

Neurodegenerative Disease Research Group, Korea Brain Research Institute, Daegu 41062, Republic of Korea
}

such tumors is the blood-brain barrier, a specific system of endothelial cells that prevents molecules in the circulating blood from non-selectively crossing into the extracellular fluid of the central nervous system to protect the neural cells and preserve neural homeostasis, which makes drug diffusion inefficient or impossible. Although there have been improvements in surgical and other therapeutic approaches, non-specificity of the potentially toxic drugs used to treat the condition remains an issue $[4,5]$. Therefore, alternative approaches to treatment of brain tumors targeting different kinds of molecules are actively being pursued.

Previously, non-coding regions of the genome, which do not translate into proteins, were regarded as junk DNA. However, high-throughput technologies have accelerated and improved our understanding of the noncoding genome. Studies have revealed that long non-coding RNAs (lncRNAs), whose transcripts are longer than 200 nucleotides, are involved in a wide range of biological processes [6] (Fig. 2). IncRNAs regulate not only gene expression but also epigenetic, transcriptional, and posttranscriptional modification, and their expression may original author(s) and the source, provide a link to the Creative Commons licence, and indicate if changes were made. The images or other third party material in this article are included in the article's Creative Commons licence, unless indicated otherwise in a credit line to the material. If material is not included in the article's Creative Commons licence and your intended use is not permitted by statutory regulation or exceeds the permitted use, you will need to obtain permission directly from the copyright holder. To view a copy of this licence, visit http://creativecommons.org/licenses/by/4.0/. The Creative Commons Public Domain Dedication waiver (http://creativeco mmons.org/publicdomain/zero/1.0/) applies to the data made available in this article, unless otherwise stated in a credit line to the data. 


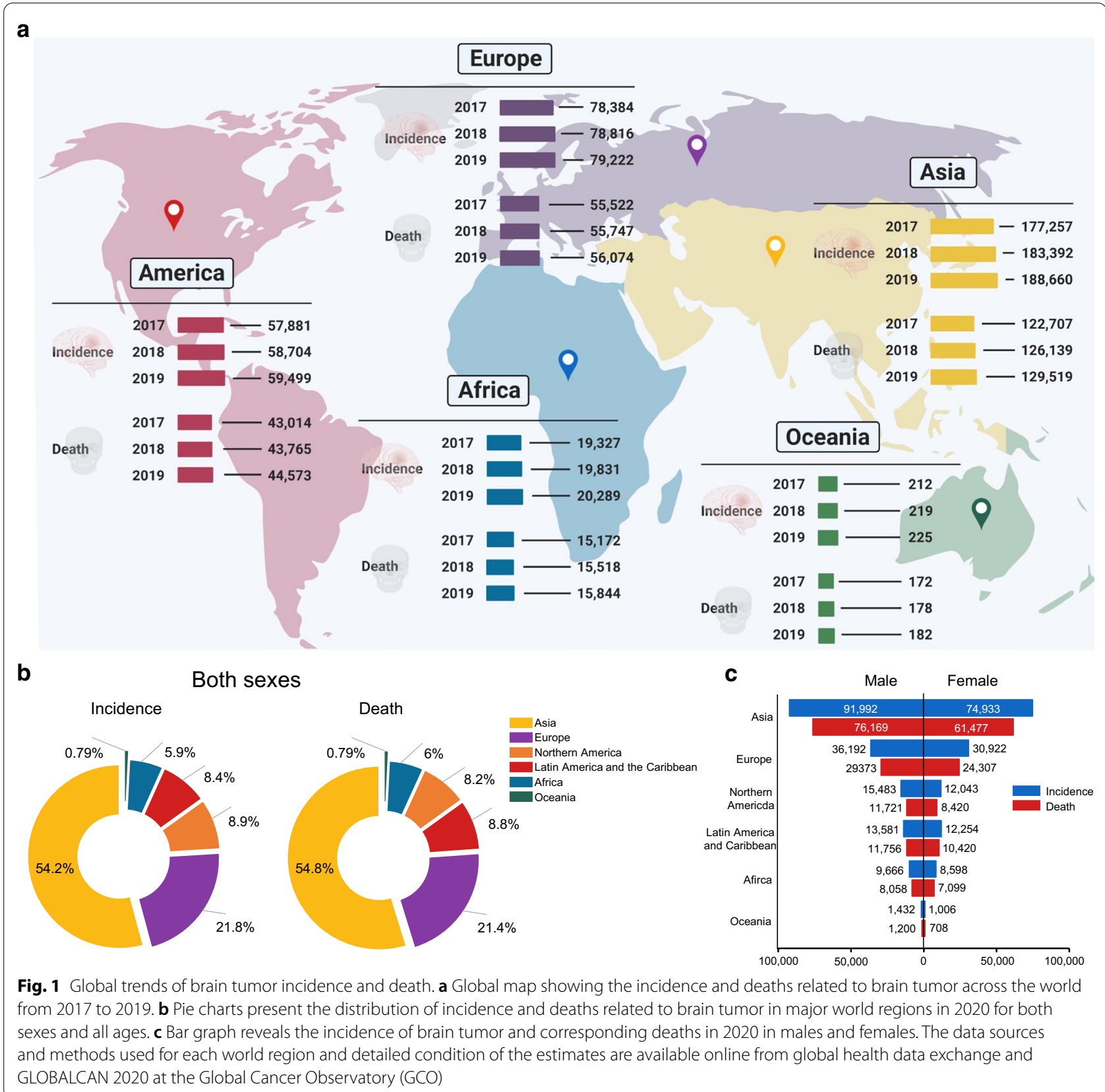

be closely related to diverse biological functions including cell survival [7-9]. In the past two decades, various roles of lncRNAs have been implicated in tumor biology [10]. The dysregulation of lncRNAs is increasingly being associated with many human diseases, especially cancers. lncRNAs exhibit unique expression patterns in various types of cancers, and play instrumental roles as cancer suppressors or promoters. Additionally, aberrant lncRNA expression in cancers has been linked to modulated expression of genes involved in tumorigenesis, metastasis, and tumor stage progression [11-16]. Moreover, several studies have revealed that lncRNAs control posttranslational modification by functioning as molecular sponges or competing endogenous RNAs (ceRNAs) that modulate microRNAs (miRNAs), which in turn regulate the expression of target genes [17-19]. Furthermore, lncRNAs are involved in signal transduction pathways, miRNA silencing, DNA damage, cell cycle control, epigenetic regulation, and hormone-driven disease states, all of which play key roles in cancer progression and metastasis [20]. 


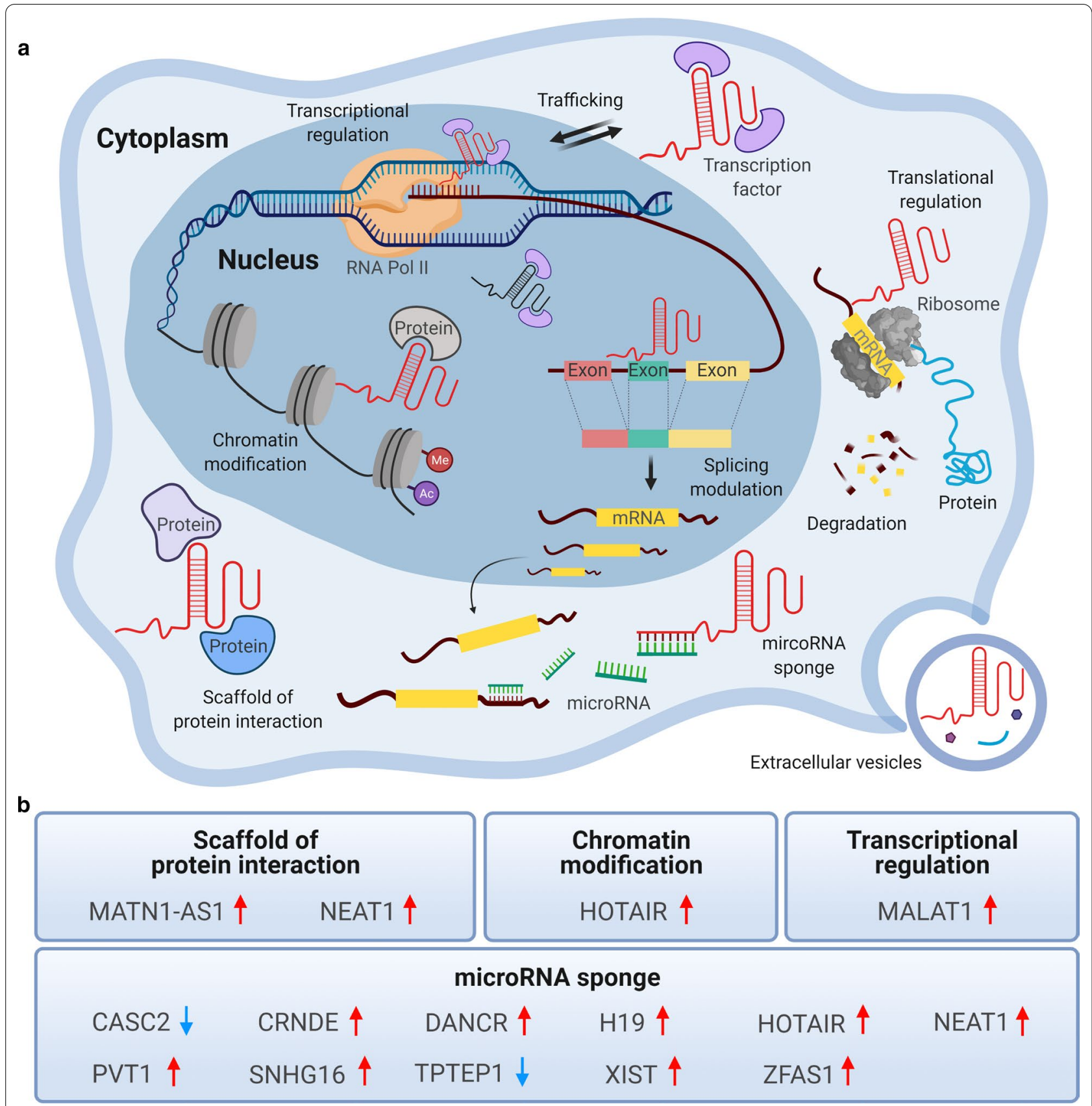

Fig. 2 Classification of IncRNAs based on their functional mechanisms. a The multiple functional roles of IncRNAs. In the nucleus, IncRNAs are involved in transcription regulation (activation or repression) via acting as transcription factors, splicing of mRNA, and chromatin modification. In the cytoplasm, they regulate translation by interacting with ribosomes, sponging miRNAs, degrading mRNAs, scaffolding protein interactions, and trafficking transcription factors. Moreover, IncRNAs can be enclosed and released by extracellular vesicles, such as exosomes. $\mathbf{b}$ The functional contributions and expression levels of reported IncRNAs in brain tumor

Recent studies have shown that aberrantly expressed lncRNAs are closely involved with the pathology and prognosis of gliomas. These studies also identified the molecular mechanisms underlying lncRNA activity, which eventually modulate biological processes in brain tumors [21]. In addition to these molecular insights, advances in genome-wide association technologies have led to the discovery of several types of lncRNAs in brain cancer. Here, we review the current understanding of the functions of lncRNAs in brain tumors 
by discussing latest findings from diverse mammalian systems.

\section{LncRNAs in signaling pathways and brain tumors}

The roles of lncRNAs and their associated pathways in gliomas have been identified, and their interactions with miRNAs have been studied [21, 22]. This section describes the mechanisms of action of lncRNAs in cellular processes and signaling pathways involved in the development of gliomas (Fig. 3).

\section{$\mathrm{PI3K} / \mathrm{Akt} / \mathrm{mTOR}$ pathway}

The PI3K/Akt/mTOR pathway is often deregulated in cancer cells, leading to enhanced cell growth, proliferation, and survival of these cells. This pathway also plays a crucial role in apoptosis and autophagy in glioma [23, 24].

The cancer susceptibility candidate 2 (CASC2) lncRNA, which is downregulated gene in various cancers including gliomas, is an important modulator of this pathway. CASC2 has been identified as a tumor suppressor that is located on chromosome 10q26 [25, 26]. CASC2 modulates glioma growth and resistance to temozolomide (TMZ), one of the most commonly used chemotherapeutic agents for glioma, by upregulating the expression of phosphatase and tensin homolog (PTEN), a known tumor suppressor involving in several cancers including gliomas and inhibits Akt signaling pathway and p-Akt pathway via direct inhibition of miR-181a [27]. Moreover, it negatively regulates miR-193a-5p expression, which in turn reduces TMZ-induced autophagy via upregulation of the mTOR pathway [28].

The differentiation antagonizing non-protein coding RNA (DANCR) lncRNA, a tumor-associated lncRNA located on chromosome 14, is upregulated in several types of human cancers [29]. Aberrant expression of DANCR in various cancers is associated with oncogenic or tumor suppressive mechanisms that are hallmarks of cancer, such as cell proliferation, invasion, and metastasis [29-31]. Additionally, DANCR upregulates AXL, a receptor tyrosine kinase that activates the PI3K/Akt/ NF- $\mathrm{KB}$ signaling pathway $[32,33]$ by competitively binding with miR-33a-5p, miRNA-33b-5p, miR-1-3p, miR206 and miR-613 to mediate the cisplatin resistance in gliomas [34].

The highly upregulated in liver cancer (HULC) lncRNA is located on chromosome 6p24.3 and highly expressed in glioma as an oncogene that contributes to tumor progression [35]. HULC silencing suppresses proliferation, adhesion, migration, invasion, and angiogenesis through

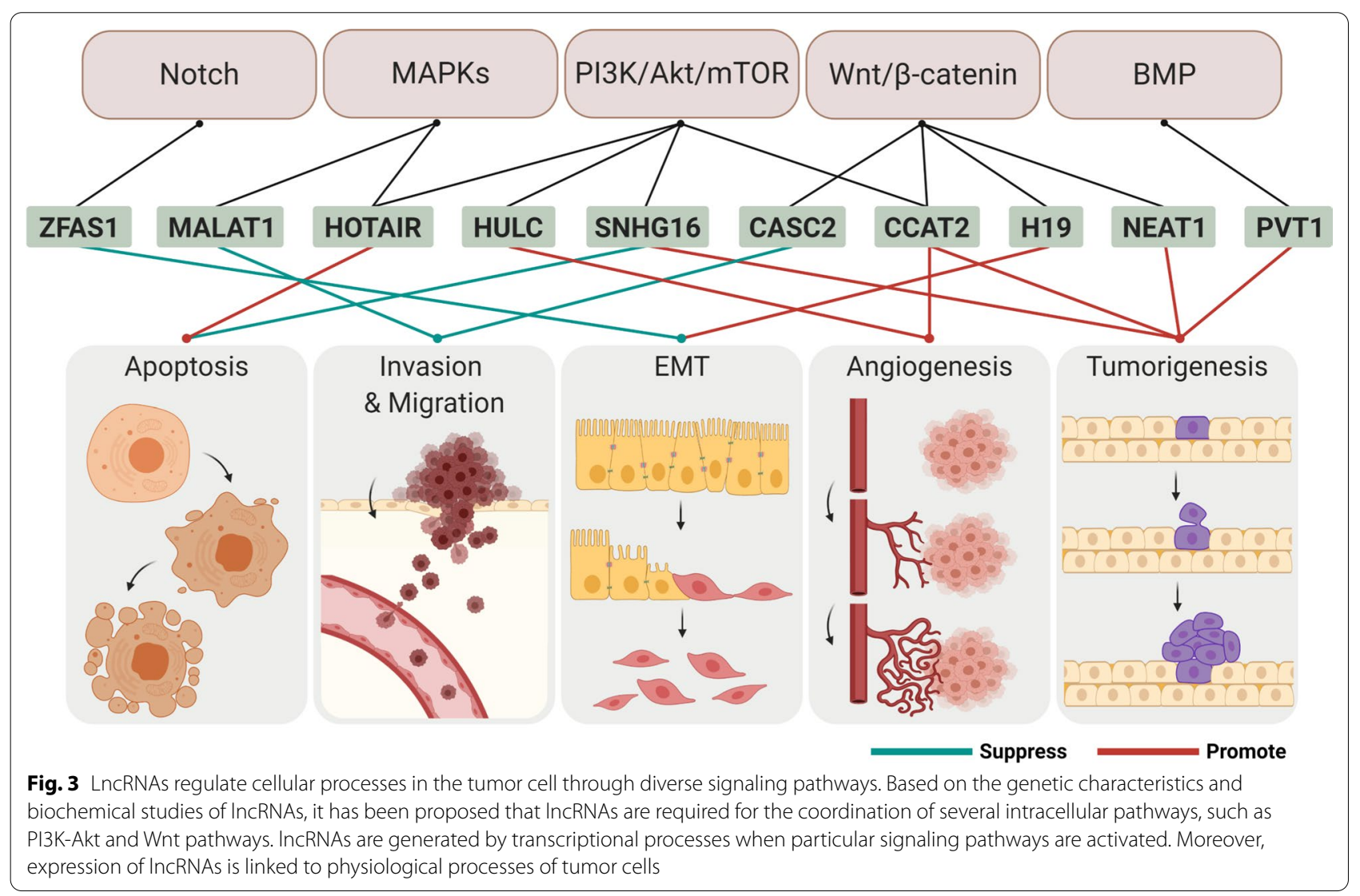


the regulation of the cell cycle and anoikis, a Greek word for "homelessness" and a critical mechanism in preventing tumor cell apoptosis via a decrease in cell-matrix interaction, in the glioma by modulating endothelial cellspecific molecule 1 (ESM-1) expression via the PI3K/Akt/ mTOR signaling pathway [36].

The small nucleolar RNA host gene 16 (SNHG16) lncRNA is highly expressed in gliomas and is correlated with short survival and poor clinicopathologic features. Knockdown of SNHG16 suppresses the viability of glioma cells and promotes apoptosis by regulating the expression of B-cell lymphoma 2 family (Bcl-2) proteins and activating the PI3K/Akt signaling pathway. Moreover, SNHG16 promotes glioma tumorigenesis by acting as the ceRNA that upregulates the expression of the miR4518 targeted gene, protein arginine methyltransferase 5 (PRMT5) by directly sponging miR-4518 [37]. Additionally, high expression of SNHG16 increases cell migration, invasion, and proliferation via the PI3K/Akt pathway and sponging of miR-373, leading to release of epidermal growth factor receptor (EGFR), which is an important receptor tyrosine kinase in tumorigenesis and a target of miR-373. Thus, SNHG16 enhances the tumorigenicity of gliomas through the miR-373/EGFR axis via the PI3K/ Akt pathway [38, 39].

The colorectal neoplasia differentially expressed (CRNDE) lncRNA, which is specifically expressed in certain regions of the human brain, is also upregulated in gliomas [40]. This IncRNA negatively regulates miR$136-5 p$ by binding as a ceRNA, thereby inhibiting Bcl-2 and Wnt2, which act downstream of the PI3K/Akt/ mTOR signaling pathway, thus enhancing the glioma malignancy [41]. Additionally, CRNDE modulates the mTOR signaling pathway; knockdown of the CRNDE decreases the phosphorylation of P70S6K, a downstream signaling molecule in the mTOR signaling pathway [42].

The HOX transcript antisense RNA (HOTAIR) lncRNA is a $\sim 2.2 \mathrm{~kb}$ lncRNA belonging to the homeobox superfamily that is transcribed from the HOXC locus at chromosome 12q13. HOTAIR acts as a negative prognostic factor for various cancers, including glioma, and its abundant expression is closely related to tumor progression [43, 44]. Knockdown of HOTAIR inhibits fibroblast growth factor 1 (FGF1) expression and blocks the activity of the PI3K/Akt and MEK1/2 pathways, leading to the suppression of malignant behavior, by upregulating miR326, which targets FGF1. This intervention induces cell cycle arrest and apoptosis, and inhibits cell migration, invasion, and proliferation in human glioma cells [45].

The X-inactive-specific transcript (XIST) lncRNA, produced by the XIST gene, is a critical regulator of cancer, levels of which correlate with cell differentiation, proliferation, and genome maintenance. Abnormal expression of XIST has been seen in various human cancers, where it plays a pathological function [46, 47]. Moreover, XIST expression levels are increased in glioma and human glioma stem cells. Attenuation of cell growth and glucose metabolism was seen in glioblastoma cells following knockdown of XIST. This effect occurs via regulation of the insulin receptor substrate 1 (IRS1)/PI3K/Akt pathway as XIST functions as the ceRNA of miR-126; in vivo, this effect reduced glioblastoma tumor growth [48].

The cancer susceptibility candidate 2 (CCAT2) lncRNA is an oncogenic 1,752 bp lncRNA located on chromosome $8 \mathrm{q} 24.21$ that is upregulated in various human cancers, including glioma [49]. CCAT2 enhances cell proliferation and endothelial angiogenesis in glioma by increasing vascular endothelial growth factor A (VEGFA) through miR-424 and activating the PI3K/Akt signaling pathway[50].

\section{MAPK pathway}

Mitogen-activated protein kinases (MAPKs) are a family of signaling molecules, which are activated by growth factors, cytokines, and environmental stress. They control crucial cellular processes, including cell growth, proliferation, migration, and apoptosis [51].

The metastasis-associated lung adenocarcinoma transcript 1 (MALAT1) lncRNA, also called nuclear-enriched transcript 2, is an $8.7 \mathrm{~kb}$ lncRNA located on chromosome 11q13. MALAT1 is known as a prognostic indicator in non-small cell lung cancer, but is abnormally expressed in various human cancers; it is upregulated in gliomas, where its expression is associated with the progression of glioma and poor prognosis [52-54]. Additionally, the tumor-suppressive function of MALAT1 is related to inhibition of the extracellular signal-regulated kinase/mitogen-activated protein kinase (ERK/MAPK) signaling pathway, which modulates cell proliferation and invasion, as well as inhibition of matrix metalloproteinase 2 (MMP2), a key enzyme in invasion. Therefore, knockdown of MALAT1 promotes cell proliferation and invasion in glioma [55]. Similarly, downregulation of MALAT1 enhances cell proliferation via activation of the MAPK pathway in glioma stem cells [56].

The downregulation of MATN1 antisense RNA 1 (MATN-AS1) lncRNA is associated with short survival duration and poor prognosis of glioblastoma patients. Upregulation of MATN1-AS2 suppressed the expression of RELA, a group of the Rel proteins family and MAPK pathway, thereby inhibiting cell proliferation and invasion through apoptosis of glioblastoma cells [57].

The transmembrane phosphatase with tensin homology pseudogene 1 (TPTEP1) lncRNA is one of the most downregulated lncRNAs in non-small cell lung cancer, where it inhibits the cell proliferation by competitively 
sponging miR-328-5p [58]. In glioma, TPTEP1 promotes the P38 MAPK pathway through competitive interactions with miR-106a-5p, thus inhibiting stemness and radioresistance [59].

\section{Wnt/ $\beta$-catenin pathway}

Wnt/ $\beta$-catenin signaling is essential in embryonic development and tissue homeostasis, and thus controls cell proliferation and cell fate. Hence, activation and mutation of the Wnt/ $\beta$-catenin pathway is associated with various human cancers and other diseases [60, 61].

Overexpression of CASC2 significantly suppresses migration, invasion, and proliferation in glioma through the inhibition of Wnt/ $\beta$-catenin signaling pathway [62].

DANCR, which is upregulated in glioma, that activates the $\mathrm{Wnt} / \beta$-catenin signaling pathway, leading to increased migration and proliferation of glioma cells. However, this tendency is reduced by si-DANCR [63].

The H19 lncRNA is located downstream of insulin growth factor 2 (IGF2) on chromosome 11p15 in humans and chromosome 7 in mice. Its expression is increased in various cancers including gliomas, where it correlates with cell growth and invasion and it plays an oncogenic role [64-67]. Furthermore, H19 expression is closely related with glioma grade [68]. Conversely, downregulation of H19 suppresses glioma cell progression, including, migration, invasion, and proliferation via suppressing the Wnt/ $\beta$-catenin signaling pathway [69]. Silencing of H19 suppresses epithelial-mesenchymal transition (EMT), which induces cell migration and decrease intercellular adhesion, and is associated with chemoresistance in various cancers, thus, decreasing chemoresistance to TMZ via suppressing the $\mathrm{Wnt} / \beta$-catenin signaling pathway [70].

The nuclear-enriched abundant transcript 1 (NEAT1) lncRNA, a $3.7 \mathrm{~kb}$ lncRNA found on chromosome 11q13.1, localizes to the nucleus and is an essential core component of the paraspeckle substructure [71, 72]. This lncRNA is upregulated in some cancers, including glioma, where it plays as an oncogene, and is involved in proliferation, migration, invasion, and impaired apoptosis [73-75]. Moreover, an increase in this lncRNA enhances progression of glioblastoma and tumorigenesis via the effects of the EGFR pathway on cell cycle regulation. This involves binding of enhancer of zeste 2 (EZH2) and the $\mathrm{Wnt} / \beta$-catenin signaling pathway [76].

Wnt inhibitory factor 1 (WIF1) attenuates non-canonical Wnt signaling through downregulation of MALAT1, thereby suppressing migration, but not proliferation, of glioblastoma cells [77].

Similarly, knockdown of CCAT2 suppresses cell migration, proliferation, cell cycle progression, and tumorigenesis in glioma by downregulating the Wnt/ $\mathrm{\beta}$ catenin signaling pathway [78].

\section{Other pathways}

In addition to these pathways, several other pathways, including the miRNA axis, bone morphogenetic protein (BMP), Notch, nuclear factor kappa-light-chainenhancer of activation $B$ cells $(N F-k B)$ pathways are involved in cancer. miRNAs are small non-coding RNAs that are 21-25 nucleotides in length, which mainly regulate expression of gene at the post-transcriptional level, and the expression of protein via binding to their target mRNAs [79]. BMP protein is a part of the transforming growth factor- $\beta$ (TGF- $\beta$ ) family and plays pivotal roles in the morphogenesis of different organs, including the neural system. BMP signaling has also been reported as a tumor promoter as well as a tumor suppressor in various types of cancer [80]. Notch signaling is a conserved ligand-receptor signaling pathway that is involved in fundamental mechanistic functions, such as cell survival, differentiation, development, and apoptosis. Dysregulation of Notch signaling has been reported in various diseases including cancer [81]. Finally, NF- $\mathrm{KB}$ is one of the longsuspected factors that mediates interactions between cancer and inflammation. NF- $\mathrm{kB}$ signaling pathway regulates cell migration, proliferation, inflammation, and apoptosis by modulating the expression of anti-apoptotic molecules and pro-inflammatory factors [82].

The overexpression of plasmacytoma variant translocation 1 (PVT1) lncRNA located on chromosome 8q24, has been reported to play an important role in tumor progression and biological processes, such as apoptosis, invasion, mobility, and proliferation in various types of cancer [83-85]. It affects the progression of glioma by targeting miRNAs, such as miR-186 [86], miR-200a [87], miR-424 [88], and miR-140-5p [89]. Knockdown of this lncRNA suppresses malignant behaviors in glioma through the binding and upregulation of miR-190a-5p and miR-488-3p, which target and inhibit myocyte enhancer factor $2 \mathrm{C}$ (MEF2C), which is also transcriptionally regulated by the oncogene jagged 1 (JAG1) [90]. Furthermore, this lncRNA modulates Gremlin 1 (GREM1) and BMP downstream signaling pathway through sponging of miR-128-3p, thereby promoting tumorigenesis and progression in gliomas [91].

As mentioned previously, CASC2, which is downregulated in glioma, modulates miRNAs. Overexpression of CASC2 inhibits glioma malignancy, migration, invasion, and proliferation and induces cell apoptosis via negative modulation of miR-21 [92].

The ZNFX1 antisense RNA 1 (ZFAS1) lncRNA located on chromosome 20q13 is another lncRNA involved in progression and metastasis of various cancers [93]. 
ZFAS1 induces glioma progression by sponging miR$150-5 p$ to regulate proteolipid protein 2 (PLP2), which is known as the functional target of miR-150-5p [94]. Inhibition of ZFAS1 significantly suppresses proliferation, migration, and invasion of glioma cells. Furthermore, ZFAS1 knockdown reduces the viability of glioma cells and increases their cisplatin chemosensitivity by targeting miR-432-5p [95]. Moreover, the EMT and the Notch signaling pathway are inactivated in the glioma cells after ZFAS1 knockdown. Thus, ZFAS1 exhibits an oncogenic role in glioma progression by regulating the EMT and the Notch signaling pathway [96].

Similarly, DANCR promotes glioma progression by acting as a sponge of miR-634, thus modulating RAB1A, which has an important role in tumor progression [97]. Furthermore, knockdown of DANCR revealed its role as the ceRNA that regulates expression of B-lymphoma Moloney murine leukemia virus insertion region-1 (BMI1), a self-renewal gene that is associated with tumorigenesis and progression of cancer in glioma [98]. Thus, knockdown of DANCR inhibits migration, invasion, and proliferation of glioma cells via sponging of miR-135a-5p [99].

The ceRNA role of SNHG16, which is overexpressed in glioma, also promotes the malignancy through the enhancement of endogenous target gene, E2F1 via sponging of miR-20a-5p [100].

Knockdown of CRNDE promotes the miR-348 expression, leading to inhibition of piwi-like RNA-mediated gene silencing 4 (PIWIL4), which has an oncogenic role in glioma, thus inhibiting the malignant progression of glioma [101]. CRNDE also downregulates miR-186, which is known to have a malignant biological role in glioma stem cells [102].

Glioma malignancy is also promoted by HOTAIR via its interactions with the polycomb repressive complex 2 (PRC2) and certain miRNAs [103]. Also, HOTAIR expression correlates with angiogenesis via modulation of VEGFA expression, one of the most important factors in tumor angiogenesis, and transmission of this factor to endothelial cells through glioma cell-derived extracellular vesicles [104]. HOTAIR also regulates glutaminase levels to enhance glioma progression via binding of miR-126-5p as a ceRNA [105]. High expression of HOTAIR was found to interact with miR-148b-3p and inhibit malignancy in glioma cell [106]. HOTAIR regulates the 3' untranslated region of spindle and kinetochore associated complex subunit 2 (SKA2), and binds the tumor suppressor miR-141 as an endogenous sponge, thus participating in the pathogenesis and progression of human gliomas [107]. Knockdown of HOTAIR increased the permeability of the blood-tumor barrier (BTB) by connecting with miR-148b-3p as a target RNA. This knockdown also decreased the levels of tight junction-correlated proteins, such as Zonula occludens 1 (ZO-1), occludin, and claudin-5, in glioma microvascular endothelial cells by targeting upstream stimulatory factor 1 (USF1), thus enabling drug delivery [108]. Finally, HOTAIR is regulated by the glioblastoma proliferative pathway, specifically by bromodomain and extra-terminal domain proteins, such as bromodomain-containing 4 (BRD4), which binds to and increases HOTAIR levels in this pathway [109].

The H19 lncRNA increases proliferation and invasion via downregulating miR-152 [110], and miR-140, which targets iASPP [111] and driving of the miR-675 [66, 68, $112,113]$. It also regulates glioma angiogenesis by inhibiting miR-29a, which targets and represses the angiogenic factor vasohibin 2 (VASH2) [114]. H19 acts as a ceRNA on miR-138, which targets HIF- $1 \alpha$ and modulates the expression of VEGF, thus promoting proliferation, migration, invasion, and angiogenesis in gliomas [115]. In addition, H19 regulates levels of the sex determining region Y-box protein 4 (SOX4) by sponging miR-130a-3p as a ceRNA. These findings indicate that this lncRNA regulates the EMT process, in which epithelial cells lose their original roles and gain migratory and invasion-related roles, becoming mesenchymal cells, as seen in various tumors [116]. H19 stimulation via oxidative stress promotes TMZ resistance through activation of the NF- $\mathrm{kB}$ signaling pathway [117].

Similarly, XIST regulates miR-429, thus promoting tumorigenicity and angiogenesis in gliomas [118]. XIST is correlated with miR-29c and modulates TMZ chemoresistance via its effects on DNA mismatch repair-related molecules, such as $\mathrm{O}^{6}$-methylguanine-DNA methyltransferase (MGMT) and specificity protein 1 (SP1) [119]. XIST also has oncogenic functions in glioma; it inhibits miR-137 by acting as a sponge, thereby increasing Rasrelated C3 botulinum toxin substrate 1(Rac1) expression [120]. Knockdown of XIST upregulates miR-137, enhancing BTB permeability and decreasing angiogenesis in glioma via inhibition of the transcription factors forkhead box $\mathrm{C} 1$ (FOXC1) and ZO-2 [121]. It also upregulates miR-152, suppressing cell cycle progression and increasing apoptosis in glioma stem cells, thus playing a tumor suppressive role [122].

NEAT1 directly targets miR-449b-5p as a molecular sponge and promotes upregulation of c-Met, a direct target of miR-449b-5p, to increase pathogenesis in glioma [123]. Meanwhile, knockdown of NEAT1 activates miRlet-7e, which acts as a cancer inhibitor by decreasing migration, invasion, and proliferation while increasing apoptosis in glioma stem cells and this leads to downregulation of NRAS protein, an isoform of RAS reported to be mutated in several cancers and known to play an oncogenic role in glioma stem cells, thus inhibiting disease 
progression [124]. Similarly, NEAT1 knockdown targets miR-132 [125], which regulates the oncogene sex determining region Y-box protein 2 (SOX2) and miR-107 [126, 127], a modulator of cyclin-dependent kinase 6 (CDK6) and CDK14; these findings were closely connected with glioma malignancy. NEAT1 knockdown also promotes BTB permeability as it binds to miR-181-5p and targets sex determining region Y-box protein 5 (SOX5). Thus, knockdown of this lncRNA reduces expression of tight junction proteins, such as ZO-1, occludin, and claudin-5 in glioma microvascular endothelial cells [128].

MALAT1 increases the level of zinc fingers and homeoboxes 1 (ZHX1), which plays a role in the carcinogenesis of several cancers including glioblastoma by acting as a transcription repressor via molecular sponging of miR199a and as a ceRNA, thereby promoting proliferation and progression of glioblastoma [129]. MALAT1 also acts as a tumor promoter, enhancing the tumorigenesis of glioma stem cells via modulation of miR-129 and subsequent suppression of SOX2 [130]. In addition, MALAT1 enhances progression of glioma cells via upregulation of Rap1B, STMN1, RAB5A, and ATG4D by sponging miR101 [131, 132]. Moreover, MALAT1 promotes chemoresistance to TMZ in glioblastoma cells by repressing miR-101[133] and miR-203 [134]. However, MALAT1 also plays tumor-suppressive roles that involve repression of miR-155 and enhancement of F-box and WD repeat domain-containing 7 (FBXW7) function, which downregulates the expression of numerous oncoproteins in glioma cells [135].

In glioma, MATN1-AS1 enhances the carcinogenesis by sponging the miR-200b/c/429 as the ceRNA to regulate chromodomain helicase DNA-binding protein 1 (CHD1), which has an important role in the determination of cell fate [136].

CCAT2 also acts as a molecular sponge to downregulate miR-424 and upregulates Chk1, thereby enhancing chemotolerance in glioma cells [137].

\section{LncRNAs and brain tumor immunity}

The immune system shows responses to pathogens that may be categorized as part of innate or adaptive immunity. Pathogen-infected cells synthesize inflammatory mediators and cytokines via transcriptional and post-transcriptional regulation of genes as part of the immune response. Such immune responses start with discriminative recognition of pathogens by certain receptors, such as toll-like receptors [138]. Toll-like receptors recognize ligands and stimulate synthesis of inflammatory factors and cytokines through transcriptional regulation of genes via transcription factors, such as NF- $\mathrm{kB}$ and post-transcriptional regulation of gene expression through miRNAs $[138,139]$. These miRNAs regulate the activation of $\mathrm{T}$ cells and the release of inflammatory cytokines, such as tumor necrosis factor $\alpha$, interleukin, and interferon $\beta$ [140-142]. Additionally, lncRNAs modulate the expression of immunogenes through transcriptional regulation [143]. LncRNAs also play various roles during an immune reaction including immune activation, immune cell migration, infiltration, antigen presentation, and antigen release as part of the immune response against cancer [144, 145]. Therefore, miRNAs and lncRNAs are important regulators involved in the activation of immunocytes during the pathology of tumor [146].

In anaplastic glioma patients, nine immune-related lncRNAs (SNHG8, PGM5-AS1, ST20-AS1, LINC00937, AGAP2-AS1, MIR155HG, TUG1, MAPKAPK5-AS1, and HCG18) have been identified. Among these, PGM5-AS1, ST20-AS1, AGAP2-AS1 and MIR155HG have been identified as risk-related genes, whereas SNHG8, LINC00937, TUGI, MAPKAPK5-AS1 and HCG18 are considered protective genes. The expression of these genes reveals differences in immune status among low- and high-risk groups. These immune-related lncRNAs directly or indirectly regulate several prognostic immune-related mRNAs [147]. Similarly, 11 immune-related lncRNA signatures have been identified in glioma patients: H19, DLGAP1. AS1, AC025171.1, PAXIP1.AS2, FEZF1.AS1, HOTAIRM1, HOXD.AS2, and ARHGEF26.AS1 are upregulated and LINC00205, WDR11.AS1, and THAP7.AS1 are downregulated in a high-risk glioma group compared to a low-risk group [148, 149]. A recent study reported four prognostic lncRNA (AK098425, AL833059, AK056155 and CR613436) that are coexpressed with protein-coding genes and are significantly associated with immune responses, such as the inflammatory response, innate immune response, and B cell-mediated immunity in glioblastomas [150]. Similarly, six immune-related lncRNA (AC005013.5, UBE2R2-AS1, ENTPD1-AS1, RP11-89C21.2, AC073115.6, and XLOC004803) were found to be closely associated with immunerelated biological processes and pathways in glioblastomas [151]. In addition, the lncRNA HOTAIR myeloid-specific 1 (HOTAIRM1), whose expression is upregulated in glioma, enhances malignancy via sponging of miR-129-5p as ceRNA and is also related to immune activation that promotes $\mathrm{T}$ cell-mediated immune responses [152]. Thus, these lncRNAs are useful for the development of specific immunotherapies for glioma patients. Targeting the immune response with cancer therapeutics is a promising new strategy for the treatment of gliomas.

\section{Exocytosis and endocytosis of IncRNA in brain tumors}

Extracellular vesicles (EVs) are nano-sized membranous and lipid bilayer vesicles. They can be divided into exosomes, ectosomes, microvesicles, and apoptotic bodies based on their biogenesis and size [153]. 
These vesicles are crucial factors in various disease processes, including in neurodegenerative diseases [154]. Exosomes ranges from 30 to $100 \mathrm{~nm}$ in diameter and are generated through the endosomal pathway by the exocytosis of multivesicular bodies from the plasma membrane. Exosomes are released by various types of cells, such as normal, immune, and tumor cells [155]. Released exosomes can be enclosed by neighboring cells or by recipient cells $[156,157]$. Moreover, exosomes can transport various types of molecules, such as proteins, mRNAs and lncRNA that play important roles in cell to cell communications. Such exchange of genetic and epigenetic information through intercellular communication promotes epigenetic changes in cells of different tissues [158]. Interestingly, lncRNAs are selectively sorted into exosomes and the released exosomal lncRNAs can reveal differences in expression levels between normal cells and cancer cells. Hence, cancer cells show discrepancies in expression of specific exosomal lncRNAs, which may be involved in various functions $[159,160]$. Several recent studies have reported the multiple functions of exosomal lncRNAs in cancer, including in tumorigenesis, angiogenesis, drug resistance, and regulation of tumor microenvironment [154, 161-163].

The POU class 3 homeobox 3 (POU3F3) lncRNA is an oncogene seen in various human cancers, such as cervical cancer, nasopharyngeal carcinoma, and breast cancer [164]. In glioma, expression of this lncRNA is upregulated and enriched exosomes released by glioma cells enhance angiogenesis [165].

Similarly, the SBF2 antisense RNA 1 (SBF2-AS1) lncRNA, located on the 11p15.1 locus, has been identified as a critical regulation factor in cancer progression [166, 167]. In glioblastoma, SBF2-AS1 can be transferred into exosomes and secretion of such oncogenic SBF2AS1-enriched exosomes promotes chemoresistance to TMZ. SBF2-AS1 acts as a ceRNA molecular sponge of miR-151a-3p, thus promoting oncogenesis [168].

CCAT2-enriched exosomes are also released by glioma cells and may also be involved in human umbilical vein endothelial cells. In these endothelial cells, upregulation of CCAT2 enhances angiogenesis via increasing vascular endothelial growth factor A and transforming growth factor $\beta$ expression and inhibits apoptosis via increasing $\mathrm{Bcl}-2$ and decreasing $\mathrm{Bcl}-2$-associated $\mathrm{X}$ (Bax) and caspase-3 expression. Therefore, the release of exosomes containing the lncRNA CCAT2 by glioma cells promotes angiogenesis and inhibits endothelial cell apoptosis [169].

LncRNA activated by transforming growth factor (TGF)- $\beta$ (lncRNA-ATB), is abnormally expressed and functions as a progression factor in various cancers, such as hepatocellular carcinoma, gastric cancer, and breast cancer [170]. This exosomal lncRNA is upregulated in glioma and activates astrocytes, but connects and suppresses miR-204-3p in astrocytes. Thus, this lncRNA enhances the invasion of glioma cells [171].

\section{Conclusions and perspectives}

In 1955, Georges Palade, the cell biologist, identified the first ncRNA, which was linked to the ribonucleotide protein complex. This was followed by discoveries of regulatory ncRNAs, such as miRNAs, ribosomal RNAs, transfer RNAs, small nuclear RNAs, short interfering RNAs, ceRNAs, enhancer RNAs, piwi-interacting RNAs, and lncRNAs in the both prokaryotic and eukaryotic organisms [172]. However, ncRNAs were considered as 'junk' products of gene transcription processes and study of the ncRNAs was hampered by the lack of genetic information in the past decades. However, the roles of ncRNAs have been gradually elucidated to understand the genetic heterogeneity and their diverse roles in biological steps, and emerging findings have revealed crucial functions of ncRNAs in transcriptional regulation. In addition, advances in genome-wide association studies (GWAS) have led to the discovery of new ncRNAs. Among the ncRNAs, diverse biological functions of lncRNAs have been identified, including in tumor biology, such as modulation of transcription and translation by acting as transcription factors, splicing of mRNA, modification of chromatin, interaction of ribosomes, sponging with miRNA, degradation of mRNAs, scaffolding of protein interactions, and trafficking of transcription factors [172]. Recently, several remarkable studies reported the relation of lncRNAs and EVs, which translocate the DNA, RNA, proteins, and lipids to other cells, resulting in diverse phenotypic responses that promote functional modulation of cellular activity in recipient cells [173, 174]. Furthermore, lncRNAs and EVs are closely related with various diseases. In addition, they are associated with tumorigenesis and tumor microenvironment [175177]. Consequently, these unique functions and biology of the EVs in cell-to-cell communications through the delivery of cargo, including mRNAs, miRNAs, and lncRNAs, make them attractive as potential therapeutics and biomarkers in various diseases [178, 179].

Molecular insights into lncRNAs-mediated intracellular pathways and transcriptional networks have provided answers for several unanswered questions in transcriptional and translational regulation. Recent observations have also revealed the roles of lncRNAs in diverse diseases and responses to various stresses. Besides, abnormal transcription and mutation of lncRNAs have been observed in many sporadic tumors [180]. Indeed, while activation or inactivation of lncRNAs might affect tumor development, cancer cells may also rely on the molecular environment. Given the potential importance of 
lncRNAs in brain tumors, they are an ideal target for oligonucleotide-based therapeutics. However, several biological issues must be resolved before their successful application as the therapeutic agents. For example, a more rigorous approach for clinical evaluation of lncRNAs for brain tumor therapeutics requires the assessment of blood-brain barrier (BBB) permeability or stability in cerebrospinal fluid exposure [181]. Although circulating lncRNAs are derived from several sources including blood and serum, identification of the lncRNAs in mammalian fluids has been hampered by a lack of genetic information. Moreover, most studies have been considered and preferred to identify miRNAs present in the fluids in diseased state as therapeutic targets compared to lncRNAs in whole blood [182]. Previously, cell-free nucleic acids, such as DNA, mRNA, and miRNA were considered as biomarkers in cancer patients [183]. Recent advances in lncRNA research, which were based on GWAS and biochemical systems, have improved the knowledge of cell-free nucleic acids including circulating lncRNAs $[184,185]$. This impressively wide range of findings can facilitate the establishment of preclinical models for identification of potent lncRNAs for application in clinical treatment in cancer [186]. Thus, it is worth studying specific interactions between lncRNAs and brain tumors, which may enable determination of IncRNA-targeted therapeutic strategies that might be used increasingly in the future.

In this review, we have summarized the current understanding of the roles of IncRNAs in brain tumors (Table 1). Understanding the various functions of gene transcripts has led to advancements in identification of biomarkers and drug development. We have reviewed recent insights into biological functions of lncRNAs that were gleaned through genetic and biochemical studies, though many unanswered questions remain. For example, the genetic or epigenetic mechanisms that regulate the expression, localization, and activity of lncRNAs are still unclear. In addition, a lack of certain transcription factors in IncRNA pathways raises the question of whether bidirectional mechanisms other than genetic functions of sense or antisense transcripts exist. Besides, it is not clear whether lncRNAs are fundamental molecules in brain tumor progression. The development of brain tumor involves several complex mechanisms regulated by multiple molecules and pathways. Cells are constantly challenged by diverse abnormalities caused by exogenous and endogenous factors. In addition, genomic instability caused by various factors is related to tumor evolution and patient outcomes [187]. In general, tumors are ascribed to genetic heterogeneity resulting from changes in processes, such as transcriptional or epigenetic regulation [188]. The biological features of IncRNAs are heterogenous; they are associated with cis- or transacting transcriptional regulation and they are involved in modulation of targeted RNAs or proteins [6]. Since the discovery of the biological roles of lncRNAs, there have been significant advances in the field of tumorigenesis [189]. Therefore, novel therapeutic approaches might also include targeting active lncRNAs that are essential for cell death or survival in brain tumors. High-throughput screening studies across several decades have focused on identifying non-coding RNAs that could serve as genomic signatures in biological systems [190]. Using this approach, the importance of lncRNAs as therapeutic targets has emerged in various cancers [189]. The diverse roles of IncRNAs in tumorigenesis could shed greater light on other undiscovered functions of lncRNAs and potentially provide new therapeutic approaches for treating brain tumors.

\section{Abbreviations}

ATB: Activated by transforming growth factor- $\beta$; $\mathrm{BCl}-2$ : B-cell lymphoma 2 family; Bax: BCl-2-associated X; BTB: Blood-tumor barrier; BBB: Blood-brain barrier; BMI1: B-lymphoma Moloney murine leukemia virus insertion region-1; BMP: Bone morphogenetic protein; BRD4: Bromodomain-containing 4; CASC2: Cancer susceptibility candidate 2; CCAT2: Cancer susceptibility candidate 2; CHD1: Chromodomain helicase DNA-binding protein 1; CRNDE: Colorectal neoplasia differentially expressed; ceRNAs: Competing endogenous RNAs; CDK6: Cyclin-dependent kinase 6; DANCR: Differentiation antagonizing non-protein coding RNA; ESM-1: Endothelial cell-specific molecule 1; EZH2: Enhancer of zeste 2; EGFR: Epidermal growth factor receptor; EMT: Epithelial-mesenchymal transition; ERK: Extracellular signal-regulated kinase; EVs: Extracellular vesicles; FBXW7: F-box and WD repeat domain-containing 7; FGF1: Fibroblast growth factor 1; FOXC1: Forkhead box C1; GWAS: Genome-wide association studies; GREM1: Gremlin 1; HULC: Highly upregulated in liver cancer; HOTAIR: HOX transcript antisense RNA; IGF2: Insulin growth factor 2; IRS1: Insulin receptor substrate 1; JAG1: Jagged 1; LncRNAs: Long non-coding RNAs; MATNAS1: MATN1 antisense RNA 1; MMP2: Matrix metalloproteinase 2; MALAT1: Metastasis-associated lung adenocarcinoma transcript 1; miRNAs: MicroRNAs; MAPKs: Mitogen-activated protein kinases; MEF2C: Myocyte enhancer factor 2C; NF-KB: Nuclear factor kappa-light-chain-enhancer of activation B cells; NEAT1: Nuclear-enriched abundant transcript 1; MGMT: O6-methylguanineDNA methyltransferase; PTEN: Phosphatase and tensin homolog; PIWIL4: Piwilike RNA-mediated gene silencing 4; PVT1: Plasmacytoma variant translocation 1; PRC2: Polycomb repressive complex 2; POU3F3: POU class 3 homeobox 3; PRMT5: Protein arginine methyltransferase 5; PLP2: Proteolipid protein 2; Rac1: Ras-related C3 botulinum toxin substrate 1; SBF2-AS1: SBF2 antisense RNA 1; SOX2: Sex determining region Y-box protein 2; SOX4: Sex determining region Y-box protein 4; SOX5: Sex determining region Y-box protein 5; SNHG16:

Small nucleolar RNA host gene 16; SP1: Specificity protein 1; SKA2: Spindle and kinetochore associated complex subunit 2; TMZ: Temozolomide; TGF- $\beta$ : Transforming growth factor- $\beta$; TPTEP1: Transmembrane phosphatase with tensin homology pseudogene 1; USF1: Upstream stimulatory factor 1; VEGFA: Vascular endothelial growth factor A; VASH2: Vasohibin 2; WIF1: Wnt inhibitory factor 1 ; XIST: X-inactive-specific transcript; ZHX1: Zinc fingers and homeoboxes 1; ZFAS1: ZNFX1 antisense RNA 1; ZO-1: Zonula occludens 1.

\section{Acknowledgements}

All graphic figures were made with biorender.com. We would like to thank Editage for English language editing.

\section{Authors' contributions}

S.-H.K., K.-H.L., S.Y., and J.-Y.J. wrote the paper. S.-H.K. and S.Y. created the figures and tables. S.-H.K. and K.-H.L. have contributed equally to this work. J.-Y.J. provided guidance and direction for manuscript. All authors read and approved the final manuscript. 
Table 1 Signaling pathway and role of IncRNA-target genes in brain tumors

\begin{tabular}{|c|c|c|c|c|}
\hline IncRNA & Target & Signaling pathway & Activity & Reference \\
\hline \multirow[t]{7}{*}{ PVT1 } & miR-128-3p & BMP pathway & Promote tumorigenesis and progression & [91] \\
\hline & miR-186 & & Promote cell proliferation, migration, and angiogenesis & {$[86]$} \\
\hline & miR-200a & & Promote cell proliferation and invasion & {$[87]$} \\
\hline & miR-424 & & $\begin{array}{l}\text { Promote cell viability, migration invasion and tumor } \\
\text { growth }\end{array}$ & [88] \\
\hline & miR-140-5p & & $\begin{array}{l}\text { Promote cell proliferation, invasion, and aerobic glyco- } \\
\text { lysis }\end{array}$ & [89] \\
\hline & miR-190a-5p/MEF2C & & Promote malignant behaviors & {$[90]$} \\
\hline & miR-488-3p/MEF2C & & & \\
\hline \multirow[t]{4}{*}{ CASC2 } & miR-181a & PTEN and Akt pathway & Inhibit cell growth and resistance to TMZ & {$[27]$} \\
\hline & miR-193a-5p & mTOR pathway & Promote TMZ cytotoxicity through autophagy inhibition & {$[28]$} \\
\hline & & Wnt/ß-catenin pathway & Inhibit cell proliferation, migration, and invasion & {$[62]$} \\
\hline & miR-21 & & $\begin{array}{l}\text { Inhibit cell proliferation, migration and invasion and } \\
\text { promote apoptosis }\end{array}$ & [92] \\
\hline \multirow[t]{3}{*}{ ZFAS1 } & & Notch pathway & Promote progression via regulating EMT & {$[96]$} \\
\hline & miR-150-5p & & Promote progression & {$[94]$} \\
\hline & miR-432-5p & & Promote viability and promote cisplatin cytotoxicity & {$[95]$} \\
\hline \multirow[t]{4}{*}{ DANCR } & & Wnt/ß-catenin pathway & Promote progression through activation EMT & {$[63]$} \\
\hline & $\begin{array}{l}\text { miR-33a-5p } \\
\text { miR-33b-5p } \\
\text { miR-1-3p } \\
\text { miR-206 } \\
\text { miR-613a }\end{array}$ & PI3K/Akt/NF-KB pathway & Promote cisplatin resistance in vitro and in vivo & {$[34]$} \\
\hline & miR-634/RAB1A & & Promote progression & {$[97]$} \\
\hline & miR-135a-5p/BMI1 & & Promote proliferation, migration, and invasion & [99] \\
\hline HULC & ESM-1 & PI3K/Akt/mTOR pathway & Promote angiogenesis by regulated ESM-1 & {$[36]$} \\
\hline \multirow[t]{3}{*}{ SNHG16 } & miR-4518/PRMT5 & PI3K/Akt pathway & $\begin{array}{l}\text { Inhibit apoptosis and promote tumorigenesis via } \\
\text { upregulating PRMT5 }\end{array}$ & {$[37]$} \\
\hline & miR-373/EGFR & PI3K/Akt pathway & Promote tumorigenesis via releasing EGFR & {$[38]$} \\
\hline & miR-20a-5p/E2F1 & & Promote malignancy through increase E2F1 & {$[100]$} \\
\hline \multirow[t]{4}{*}{ CRNDE } & miR-136-5p/Bcl-2, Wnt2 & PI3K/Akt/mTOR pathway & Promote malignancy via inhibiting $\mathrm{Bcl}-2$ and Wnt2 & {$[41]$} \\
\hline & P70S6K & mTOR pathway & $\begin{array}{l}\text { Promote cell growth and invasion via increasing phos- } \\
\text { phorylation of P70S6K }\end{array}$ & {$[42]$} \\
\hline & miR-348/PIWIL4 & & Promote malignant progression via enhancing PIWIL4 & {$[101]$} \\
\hline & miR-186 & & $\begin{array}{l}\text { Promote cell proliferation, migration, invasion, and tumor } \\
\text { growth by inhibiting apoptosis }\end{array}$ & {$[102]$} \\
\hline \multirow[t]{8}{*}{ HOTAIR } & miR326/FGF1 & PI3K/Akt and MEK1/2 pathway & Promote apoptosis and cell cycle via inhibiting FGF1 & {$[45]$} \\
\hline & PRC2 & & Promote cell cycle progression via interacting PRC2 & {$[103]$} \\
\hline & VEGFA & & Promote angiogenesis via increasing VEGFA & {$[104]$} \\
\hline & miR-126-5p/GLS & & Promote progression via regulating GLS & {$[105]$} \\
\hline & miR-148-3p & & Inhibit malignant biological behaviors & {$[106]$} \\
\hline & miR-141/SKA2 & & Promote progression and tumor growth & {$[107]$} \\
\hline & miR-148-3p/USF1 & & Inhibit BTB permeability via promoting USF1 & [108] \\
\hline & BRD4 & & Promote proliferation by regulation of BRD4 & [109] \\
\hline \multirow[t]{7}{*}{$\mathrm{H} 19$} & & NF-kB pathway & Promote TMZ resistance & {$[117]$} \\
\hline & & Wnt/ß-catenin pathway & Promote proliferation, migration, and invasion & [69] \\
\hline & & Wnt/ß-catenin pathway & Promote TMZ resistance through suppressed EMT & [70] \\
\hline & miR-152 & & Promote proliferation and invasion & [110] \\
\hline & miR-140/iASPP & & Promote proliferation and invasion by targeting iASPP & [111] \\
\hline & miR-675 & & $\begin{array}{l}\text { Promote proliferation, migration invasion and tumor } \\
\text { growth }\end{array}$ & {$[66,68,112,113]$} \\
\hline & miR-29a/NASH2 & & Promote angiogenesis & {$[114]$} \\
\hline
\end{tabular}


Table 1 (continued)

\begin{tabular}{|c|c|c|c|c|}
\hline IncRNA & Target & Signaling pathway & Activity & Reference \\
\hline & miR-138/HIF-1a & & $\begin{array}{l}\text { Promote proliferation, migration, invasion, and angio- } \\
\text { genesis by targeting } \mathrm{HIF-1a}\end{array}$ & [115] \\
\hline & miR-130a-3p/SOX4 & & $\begin{array}{l}\text { Promote migration, invasion and EMT via regulating } \\
\text { SOX4 }\end{array}$ & [116] \\
\hline \multirow[t]{6}{*}{ XIST } & miR-126/IRS1 & PI3K/Akt pathway & $\begin{array}{l}\text { Promote cell growth, glucose metabolism and tumor } \\
\text { growth via regulating IRS1 }\end{array}$ & {$[48]$} \\
\hline & miR-429 & & Promote angiogenesis and tumorigenicity & [118] \\
\hline & miR-29c/SP1/MGMT & & $\begin{array}{l}\text { Promote proliferation and TMZ resistance through the } \\
\text { DNA mismatch repair pathway }\end{array}$ & [119] \\
\hline & miR-137/Rac1 & & Promote progression by upregulated Rac1 & [120] \\
\hline & miR-137/FOXC1/ZO-2 & & $\begin{array}{l}\text { Inhibit BTB permeability and promote angiogenesis by } \\
\text { increasing FOXC1 and ZO-2 }\end{array}$ & [121] \\
\hline & miR-152 & & Promote progression and decrease apoptosis & [122] \\
\hline \multirow[t]{6}{*}{ NEAT1 } & EGFR & Wnt/ß-catenin pathway & Promote progression and tumorigenesis through EGFR & {$[76]$} \\
\hline & miR-449b-5p/c-Met & & Promote pathogenesis by upregulated c-Met & [123] \\
\hline & miR-let-7e/NRAS & & $\begin{array}{l}\text { Promote proliferation migration and invasion while } \\
\text { inhibit apoptosis by upregulated NRAS }\end{array}$ & {$[124]$} \\
\hline & miR-132/SOX2 & & $\begin{array}{l}\text { Promote migration and invasion through upregulation } \\
\text { of SOX2 }\end{array}$ & {$[125]$} \\
\hline & miR-107/CDK6, 14 & & Promote malignant progression by promoted CDK6, 14 & {$[126,127]$} \\
\hline & miR-181-5p/SOX5 & & Inhibit BTB permeability via upregulating SOX5 & [128] \\
\hline \multirow[t]{7}{*}{ MALAT1 } & WIF1 & Non-canonical Wnt pathway & Promote migration via regulating of WIF1 & {$[77]$} \\
\hline & & ERK/MAPK pathway & Inhibit proliferation and invasion & {$[55,56]$} \\
\hline & miR-199a/ZHX1 & & Promote proliferation and progression by increase ZHX1 & [129] \\
\hline & miR-129/SOX2 & & Promote tumorigenesis via facilitating of SOX2 & [130] \\
\hline & miR-101 & & Promote progression and $\mathrm{TMZ}$ resistance & [131-133] \\
\hline & miR-203 & & Promote TMZ resistance & [134] \\
\hline & miR-155/FBXW7 & & Inhibit cell viability by upregulated FBXW7 & {$[135]$} \\
\hline \multirow[t]{2}{*}{ MATN1-AS1 } & RELA & MAPK pathway & $\begin{array}{l}\text { Inhibit cell proliferation and invasion through the } \\
\text { apoptosis }\end{array}$ & {$[57]$} \\
\hline & miR-200b/c/429/CHD1 & & Promote glioma progression & {$[136]$} \\
\hline TPTEP1 & miR-106a-5p & P38 MAPK pathway & Inhibit stemness and radio resistance & {$[59]$} \\
\hline \multirow[t]{4}{*}{ CCAT2 } & miR-424/NEGFA & PI3K/Akt pathway & $\begin{array}{l}\text { Promote proliferation and angiogenesis via increasing } \\
\text { VEGFA }\end{array}$ & {$[50]$} \\
\hline & & Wnt/ß-catenin pathway & $\begin{array}{l}\text { Promote proliferation, migration, cell cycle and tumori- } \\
\text { genesis }\end{array}$ & {$[78]$} \\
\hline & miR-424/Chk1 & & Promote chemodrug resistance by upregulated Chk1 & [137] \\
\hline & & & $\begin{array}{l}\text { Promote angiogenesis and inhibit endothelial cell apop- } \\
\text { tosis through release CCAT2-enriched exosomes }\end{array}$ & [169] \\
\hline PGM5-AS1 & risk-related genes & & Regulate several prognostic immune-related mRNA & {$[147]$} \\
\hline \multicolumn{5}{|l|}{ ST20-AS1 } \\
\hline \multicolumn{5}{|l|}{ AGAP2-AS1 } \\
\hline \multicolumn{5}{|l|}{ MIR155HG } \\
\hline SNHG8 & protective genes & & Regulate several prognostic immune-related mRNA & \\
\hline \multicolumn{5}{|l|}{ LINC00937 } \\
\hline \multicolumn{5}{|l|}{ TUGl } \\
\hline \multicolumn{5}{|l|}{ MAPKAPK5-AS1 } \\
\hline \multicolumn{5}{|l|}{ HCG18 } \\
\hline AK098425 & protein coding gene & & Associate immune-related biological immunity & {$[150]$} \\
\hline \multicolumn{5}{|l|}{ AL833059 } \\
\hline \multicolumn{5}{|l|}{ AK056155 } \\
\hline CR613436 & & & & \\
\hline
\end{tabular}


Table 1 (continued)

\begin{tabular}{|c|c|c|c|c|}
\hline IncRNA & Target & Signaling pathway & Activity & Reference \\
\hline AC005013.5 & protein coding gene & & $\begin{array}{l}\text { Associate immune-related biological process and } \\
\text { pathway }\end{array}$ & {$[151]$} \\
\hline \multicolumn{5}{|l|}{ UBE2R2-AS1 } \\
\hline \multicolumn{5}{|c|}{ RP11-89C21.2 } \\
\hline \multicolumn{5}{|l|}{ AC073115.6 } \\
\hline \multicolumn{5}{|l|}{ XLOC-004803 } \\
\hline HOTAIRM1 & miR-129-5p & & Promote malignancy and relate immune activation & {$[152]$} \\
\hline POU3F3 & & & $\begin{array}{l}\text { Promote angiogenesis and release POU3F3-enriched } \\
\text { exosomes }\end{array}$ & {$[165]$} \\
\hline SBF2-AS1 & miR-151a-3p & & $\begin{array}{l}\text { Promote TMZ resistance and secret SBF2-AS1-enriched } \\
\text { exosomes }\end{array}$ & {$[168]$} \\
\hline ATB & miR-204-3p & & $\begin{array}{l}\text { Promote cell activation and invasion through release } \\
\text { ATB-enriched exosomes }\end{array}$ & {$[171]$} \\
\hline
\end{tabular}

\section{Funding}

This work was supported by Korea Brain Research Institute (KBRI) basic research program through $\mathrm{KBRI}$ funded by the Ministry of Science and ICT (21-BR-02-09), and Basic Science Research Program through the National Research Foundation of Korea (NRF) funded by the Ministry of Education (2019R1F1A1059595).

\section{Availability of data and materials \\ Not applicable.}

\section{Declarations}

Ethical approval and consent to participate

Not applicable.

\section{Consent for publication}

Not applicable.

\section{Competing interests}

The authors declare no competing financial interests.

Received: 22 March 2021 Accepted: 3 May 2021

Published online: 12 May 2021

\section{References}

1. Miranda-Filho A, Pineros M, Soerjomataram I, Deltour I, Bray F. Cancers of the brain and CNS: global patterns and trends in incidence. Neuro Oncol. 2017:19(2):270-80.

2. Wesseling P, Capper D. WHO 2016 classification of gliomas. Neuropathol Appl Neurobiol. 2018:44(2):139-50.

3. Behnan J, Finocchiaro G, Hanna G. The landscape of the mesenchymal signature in brain tumours. Brain. 2019;142(4):847-66.

4. Jovcevska I, Kocevar N, Komel R. Glioma and glioblastoma-how much do we (not) know? Mol Clin Oncol. 2013;1 (6):935-41.

5. Poon CC, Sarkar S, Yong VW, Kelly JJP. Glioblastoma-associated microglia and macrophages: targets for therapies to improve prognosis. Brain. 2017;140(6):1548-60.

6. Kopp F, Mendell JT. Functional classification and experimental dissection of long noncoding RNAs. Cell. 2018;172(3):393-407.

7. Wei CW, Luo T, Zou SS, Wu AS. The role of long noncoding rnas in central nervous system and neurodegenerative diseases. Front Behav Neurosci. 2018;12:175.

8. Bali KK, Kuner R. Noncoding RNAs: key molecules in understanding and treating pain. Trends Mol Med. 2014;20(8):437-48.

9. Batista PJ, Chang HY. Long noncoding RNAs: cellular address codes in development and disease. Cell. 2013:152(6):1298-307.
10. Poliseno L, Salmena L, Zhang J, Carver B, Haveman WJ, Pandolfi PP. A coding-independent function of gene and pseudogene mRNAs regulates tumour biology. Nature. 2010;465(7301):1033-8.

11. Pickard MR, Mourtada-Maarabouni M, Williams GT. Long non-coding RNA GAS5 regulates apoptosis in prostate cancer cell lines. Biochim Biophys Acta. 2013;1832(10):1613-23.

12. Luo M, Li Z, Wang W, Zeng Y, Liu Z, Qiu J. Long non-coding RNA H19 increases bladder cancer metastasis by associating with $\mathrm{EZH} 2$ and inhibiting E-cadherin expression. Cancer Lett. 2013;333(2):213-21.

13. Sun W, Wu Y, Yu X, Liu Y, Song H, Xia T, Xiao B, Guo J. Decreased expression of long noncoding RNA AC096655.1-002 in gastric cancer and its clinical significance. Tumour Biol. 2013;34(5):2697-701.

14. Thai P, Statt S, Chen CH, Liang E, Campbell C, Wu R. Characterization of a novel long noncoding RNA, SCAL1, induced by cigarette smoke and elevated in lung cancer cell lines. Am J Respir Cell Mol Biol. 2013:49(2):204-11

15. Ge X, Chen Y, Liao X, Liu D, Li F, Ruan H, Jia W. Overexpression of long noncoding RNA PCAT-1 is a novel biomarker of poor prognosis in patients with colorectal cancer. Med Oncol. 2013;30(2):588.

16. Iyer MK, Niknafs YS, Malik R, Singhal U, Sahu A, Hosono Y, Barrette TR, Prensner JR, Evans JR, Zhao S, et al. The landscape of long noncoding RNAs in the human transcriptome. Nat Genet. 2015:47(3):199-208.

17. Karreth FA, Pandolfi PP. ceRNA cross-talk in cancer: when ce-bling rivalries go awry. Cancer Discov. 2013;3(10):1113-21.

18. Yang C, Wu D, Gao L, Liu X, Jin Y, Wang D, Wang T, Li X. Competing endogenous RNA networks in human cancer: hypothesis, validation, and perspectives. Oncotarget. 2016;7(12):13479-90.

19. Li F, Li Q, Wu X. Construction and analysis for differentially expressed long non-coding RNAs and MicroRNAs mediated competing endogenous RNA network in colon cancer. PLoS ONE. 2018;13(2):e0192494.

20. Sahu A, Singhal U, Chinnaiyan AM. Long noncoding RNAs in cancer: from function to translation. Trends Cancer. 2015;1(2):93-109.

21. Li J, Zhu Y, Wang H, Ji X. Targeting long noncoding RNA in glioma: a pathway perspective. Mol Ther Nucleic Acids. 2018;13:431-41.

22. Shi J, Dong B, Cao J, Mao Y, Guan W, Peng Y, Wang S. Long non-coding RNA in glioma: signaling pathways. Oncotarget. 2017:8(16):27582-92

23. Choi EJ, Cho BJ, Lee DJ, Hwang YH, Chun SH, Kim HH, Kim IA. Enhanced cytotoxic effect of radiation and temozolomide in malignant glioma cells: targeting PI3K-AKT-mTOR signaling, HSP90 and histone deacetylases. BMC Cancer. 2014;14:17.

24. Willems L, Tamburini J, Chapuis N, Lacombe C, Mayeux P, Bouscary D. $\mathrm{PI} 3 \mathrm{~K}$ and mTOR signaling pathways in cancer: new data on targeted therapies. Curr Oncol Rep. 2012;14(2):129-38.

25. Baldinu P, Cossu A, Manca A, Satta MP, Sini MC, Rozzo C, Dessole S, Cherchi P, Gianfrancesco F, Pintus A, et al. Identification of a novel candidate gene, CASC2, in a region of common allelic loss at chromosome 10q26 in human endometrial cancer. Hum Mutat. 2004;23(4):318-26. 
26. Palmieri G, Paliogiannis P, Sini MC, Manca A, Palomba G, Doneddu V, Tanda F, Pascale MR, Cossu A. Long non-coding RNA CASC2 in human cancer. Crit Rev Oncol Hematol. 2017;111:31-8.

27. Liao Y, Shen L, Zhao H, Liu Q, Fu J, Guo Y, Peng R, Cheng L. LncRNA CASC2 interacts with miR-181a to modulate glioma growth and resistance to TMZ through PTEN pathway. J Cell Biochem. 2017;118(7):1889-99.

28. Jiang C, Shen F, Du J, Fang X, Li X, Su J, Wang X, Huang X, Liu Z. Upregulation of CASC2 sensitized glioma to temozolomide cytotoxicity through autophagy inhibition by sponging miR-193a-5p and regulating mTOR expression. Biomed Pharmacother. 2018;97:844-50.

29. Thin KZ, Liu X, Feng X, Raveendran S, Tu JC. LncRNA-DANCR: A valuable cancer related long non-coding RNA for human cancers. Pathol Res Pract. 2018;214(6):801-5.

30. Jin L, Fu H, Quan J, Pan X, He T, Hu J, Li Y, Li H, Yang Y, Ye J, et al. Overexpression of long non-coding RNA differentiation antagonizing non-protein coding RNA inhibits the proliferation, migration and invasion and promotes apoptosis of renal cell carcinoma. Mol Med Rep. 2017;16(4):4463-8.

31. Sha S, Yuan D, Liu Y, Han B, Zhong N. Targeting long non-coding RNA DANCR inhibits triple negative breast cancer progression. Biol Open. 2017;6(9):1310-6.

32. Elkabets M, Pazarentzos E, Juric D, Sheng Q, Pelossof RA, Brook S, Benzaken AO, Rodon J, Morse N, Yan JJ, et al. AXL mediates resistance to PI3Kalpha inhibition by activating the EGFR/PKC/mTOR axis in head and neck and esophageal squamous cell carcinomas. Cancer Cell. 2015;27(4):533-46.

33. Stitt TN, Conn G, Gore M, Lai C, Bruno J, Radziejewski C, Mattsson K, Fisher J, Gies DR, Jones PF, et al. The anticoagulation factor protein $\mathrm{S}$ and its relative, Gas6, are ligands for the Tyro 3/Axl family of receptor tyrosine kinases. Cell. 1995;80(4):661-70.

34. Ma Y, Zhou G, Li M, Hu D, Zhang L, Liu P, Lin K. Long noncoding RNA DANCR mediates cisplatin resistance in glioma cells via activating AXL/PI3K/Akt/NF-kappaB signaling pathway. Neurochem Int. 2018;118:233-41.

35. Yang YR, Jung JH, Kim SJ, Hamada K, Suzuki A, Kim HJ, Lee JH, Kwon OB, Lee YK, Kim J, et al. Forebrain-specific ablation of phospholipase Cgamma1 causes manic-like behavior. Mol Psychiatry. 2017;22(10):1473-82.

36. Zhu Y, Zhang X, Qi L, Cai Y, Yang P, Xuan G, Jiang Y. HULC long noncoding RNA silencing suppresses angiogenesis by regulating ESM-1 via the PI3K/Akt/mTOR signaling pathway in human gliomas. Oncotarget. 2016;7(12):14429-40.

37. Lu YF, Cai XL, Li ZZ, Lv J, Xiang YA, Chen JJ, Chen WJ, Sun WY, Liu XM, Chen JB. LnCRNA SNHG16 functions as an oncogene by sponging MiR-4518 and up-regulating PRMT5 expression in glioma. Cell Physiol Biochem. 2018;45(5):1975-85.

38. Zhou XY, Liu H, Ding ZB, Xi HP, Wang GW. IncRNA SNHG16 promotes glioma tumorigenicity through miR-373/EGFR axis by activating PI3K AKT pathway. Genomics. 2020;112(1):1021-9.

39. Lee JH, Liu R, Li J, Zhang C, Wang Y, Cai Q, Qian X, Xia Y, Zheng Y, Piao $Y$, et al. Stabilization of phosphofructokinase 1 platelet isoform by AKT promotes tumorigenesis. Nat Commun. 2017:8(1):949.

40. Ellis BC, Molloy PL, Graham LD. CRNDE: a long non-coding RNA involved in cancer, neurobiology, and development. Front Genet. 2012;3:270.

41. Li DX, Fei XR, Dong YF, Cheng CD, Yang Y, Deng XF, Huang HL, Niu WX, Zhou CX, Xia CY, et al. The long non-coding RNA CRNDE acts as a ceRNA and promotes glioma malignancy by preventing miR136-5p-mediated downregulation of $\mathrm{BCl}-2$ and Wnt2. Oncotarget. 2017;8(50):88163-78.

42. Wang $Y$, Wang Y, Li J, Zhang Y, Yin H, Han B. CRNDE, a long-noncoding RNA, promotes glioma cell growth and invasion through mTOR signaling. Cancer Lett. 2015;367(2):122-8.

43. Zhang Y, Zhang K, Luo Z, Liu L, Wu L, Liu J. Circulating long non-coding HOX transcript antisense intergenic ribonucleic acid in plasma as a potential biomarker for diagnosis of breast cancer. Thorac Cancer. 2016;7(6):627-32.

44. Zhang JX, Han L, Bao ZS, Wang YY, Chen LY, Yan W, Yu SZ, Pu PY, Liu N, You YP, et al. HOTAIR, a cell cycle-associated long noncoding RNA and a strong predictor of survival, is preferentially expressed in classical and mesenchymal glioma. Neuro Oncol. 2013;15(12):1595-603.

45. Ke J, Yao YL, Zheng J, Wang P, Liu YH, Ma J, Li Z, Liu XB, Li ZQ, Wang ZH, et al. Knockdown of long non-coding RNA HOTAIR inhibits malignant biological behaviors of human glioma cells via modulation of miR-326. Oncotarget. 2015;6(26):21934-49.

46. Weakley SM, Wang H, Yao Q, Chen C. Expression and function of a large non-coding RNA gene XIST in human cancer. World J Surg. 2011:35(8):1751-6.

47. Brown CJ, Ballabio A, Rupert JL, Lafreniere RG, Grompe M, Tonlorenzi R, Willard HF. A gene from the region of the human $X$ inactivation centre is expressed exclusively from the inactive $X$ chromosome. Nature. 1991;349(6304):38-44.

48. Cheng Z, Luo C, Guo Z. LncRNA-XIST/microRNA-126 sponge mediates cell proliferation and glucose metabolism through the IRS1/PI3K/Akt pathway in glioma. J Cell Biochem. 2020;121(3):2170-83.

49. Xin Y, Li Z, Zheng H, Chan MTV, Ka Kei Wu W. CCAT2: a novel oncogenic long non-coding RNA in human cancers. Cell Prolif. 2017;50(3):1-4.

50. Sun SL, Shu YG, Tao MY. LncRNA CCAT2 promotes angiogenesis in glioma through activation of VEGFA signalling by sponging miR-424. Mol Cell Biochem. 2020;468(1-2):69-82.

51. Dhillon AS, Hagan S, Rath O, Kolch W. MAP kinase signalling pathways in cancer. Oncogene. 2007;26(22):3279-90.

52. Ji P, Diederichs S, Wang W, Boing S, Metzger R, Schneider PM, Tidow N, Brandt B, Buerger H, Bulk E, et al. MALAT-1, a novel noncoding RNA, and thymosin beta4 predict metastasis and survival in early-stage non-small cell lung cancer. Oncogene. 2003;22(39):8031-41.

53. Yoshimoto R, Mayeda A, Yoshida M, Nakagawa S. MALAT1 long noncoding RNA in cancer. Biochim Biophys Acta. 2016;1859(1):192-9.

54. Ma KX, Wang HJ, Li XR, Li T, Su G, Yang P, Wu JW. Long noncoding RNA MALAT1 associates with the malignant status and poor prognosis in glioma. Tumour Biol. 2015;36(5):3355-9.

55. Han Y, Wu Z, Wu T, Huang Y, Cheng Z, Li X, Sun T, Xie X, Zhou Y, Du Z. Tumor-suppressive function of long noncoding RNA MALAT1 in glioma cells by downregulation of MMP2 and inactivation of ERK/MAPK signaling. Cell Death Dis. 2016;7:e2123.

56. Han Y, Zhou L, Wu T, Huang Y, Cheng Z, Li X, Sun T, Zhou Y, Du Z. Downregulation of IncRNA-MALAT1 affects proliferation and the expression of stemness markers in glioma stem cell line SHG139S. Cell Mol Neurobiol. 2016;36(7):1097-107.

57. Han N, Yang L, Zhang X, Zhou Y, Chen R, Yu Y, Dong Z, Zhang M. LnCRNA MATN1-AS1 prevents glioblastoma cell from proliferation and invasion via RELA regulation and MAPK signaling pathway. Ann Transl Med. 2019;7(23):784.

58. Cao F, Wang Z, Feng Y, Zhu H, Yang M, Zhang S, Wang X. IncRNA TPTEP1 competitively sponges miR3285p to inhibit the proliferation of nonsmall cell lung cancer cells. Oncol Rep. 2020;43(5):1606-18.

59. Tang T, Wang LX, Yang ML, Zhang RM. IncRNA TPTEP1 inhibits stemness and radioresistance of glioma through miR106a5pmediated P38 MAPK signaling. Mol Med Rep. 2020;22(6):4857-67.

60. Gong A, Huang S. FoxM1 and Wnt/beta-catenin signaling in glioma stem cells. Cancer Res. 2012;72(22):5658-62.

61. MacDonald BT, Tamai K, He X. Wnt/beta-catenin signaling: components, mechanisms, and diseases. Dev Cell. 2009;17(1):9-26.

62. Wang R, Li Y, Zhu G, Tian B, Zeng W, Yang Y, Li Z. Long noncoding RNA CASC2 predicts the prognosis of glioma patients and functions as a suppressor for gliomas by suppressing Wnt/beta-catenin signaling pathway. Neuropsychiatr Dis Treat. 2017;13:1805-13.

63. Li J, Zhou L. Overexpression of InCRNA DANCR positively affects progression of glioma via activating Wnt/beta-catenin signaling. Biomed Pharmacother. 2018;102:602-7.

64. Raveh E, Matouk IJ, Gilon M, Hochberg A. The H19 Long non-coding RNA in cancer initiation, progression and metastasis - a proposed unifying theory. Mol Cancer. 2015;14:184.

65. Gabory A, Ripoche MA, Yoshimizu T, Dandolo L. The H19 gene: regulation and function of a non-coding RNA. Cytogenet Genome Res. 2006;113(1-4):188-93.

66. Keniry A, Oxley D, Monnier P, Kyba M, Dandolo L, Smits G, Reik W. The $\mathrm{H} 19$ lincRNA is a developmental reservoir of miR-675 that suppresses growth and Igf1r. Nat Cell Biol. 2012;14(7):659-65. 
67. Jiang X, Yan Y, Hu M, Chen X, Wang Y, Dai Y, Wu D, Wang Y, Zhuang Z, $\mathrm{Xia} \mathrm{H}$. Increased level of $\mathrm{H} 19$ long noncoding RNA promotes invasion, angiogenesis, and stemness of glioblastoma cells. J Neurosurg. 2016;2016(1):129-36.

68. Shi Y, Wang Y, Luan W, Wang P, Tao T, Zhang J, Qian J, Liu N, You Y. Long non-coding RNA H19 promotes glioma cell invasion by deriving miR675. PLOS ONE. 2014;9(1):e86295.

69. Guan N, Wang R, Guo WS, Lai YJ, Zhang YD, Cheng YY. Long noncoding RNA H19 regulates the development of gliomas through the Wnt/beta-catenin signaling pathway. Eur Rev Med Pharmacol Sci. 2019;23(10):4243-53.

70. Jia L, Tian Y, Chen Y, Zhang G. The silencing of LncRNA-H19 decreases chemoresistance of human glioma cells to temozolomide by suppressing epithelial-mesenchymal transition via the Wnt/beta-Catenin pathway. Onco Targets Ther. 2018;11:313-21.

71. Clemson CM, Hutchinson JN, Sara SA, Ensminger AW, Fox AH, Chess A, Lawrence JB. An architectural role for a nuclear noncoding RNA: NEAT1 RNA is essential for the structure of paraspeckles. Mol Cell. 2009;33(6):717-26.

72. Naganuma T, Hirose T. Paraspeckle formation during the biogenesis of long non-coding RNAs. RNA Biol. 2013;10(3):456-61.

73. Wu Y, Wang H. LncRNA NEAT1 promotes dexamethasone resistance in multiple myeloma by targeting miR-193a/MCL1 pathway. J Biochem Mol Toxicol. 2018;32(1):1-6.

74. Fang J, Qiao F, Tu J, Xu J, Ding F, Liu Y, Akuo BA, Hu J, Shao S. High expression of long non-coding RNA NEAT1 indicates poor prognosis of human cancer. Oncotarget. 2017:8(28):45918-27.

75. Chakravarty D, Sboner A, Nair SS, Giannopoulou E, Li R, Hennig S, Mosquera JM, Pauwels J, Park K, Kossai M, et al. The oestrogen receptor alpha-regulated IncRNA NEAT1 is a critical modulator of prostate cancer. Nat Commun. 2014;5:5383.

76. Chen Q, Cai J, Wang Q, Wang Y, Liu M, Yang J, Zhou J, Kang C, Li M, Jiang C. Long noncoding RNA NEAT1, regulated by the EGFR pathway, contributes to glioblastoma progression through the WNT/beta-catenin pathway by scaffolding EZH2. Clin Cancer Res. 2018;24(3):684-95.

77. Vassallo I, Zinn P, Lai M, Rajakannu P, Hamou MF, Hegi ME. WIF1 reexpression in glioblastoma inhibits migration through attenuation of non-canonical WNT signaling by downregulating the InCRNA MALAT1. Oncogene. 2016;35(1):12-21.

78. Guo H, Hu G, Yang Q, Zhang P, Kuang W, Zhu X, Wu L. Knockdown of long non-coding RNA CCAT2 suppressed proliferation and migration of glioma cells. Oncotarget. 2016;7(49):81806-14

79. He L, Hannon GJ. MicroRNAs: Small RNAs with a big role in gene regulation. Nat Rev Genet. 2004;5(7):522-31.

80. Fukuda T, Fukuda R, Tanabe R, Koinuma D, Koyama H, Hashizume Y, Moustakas A, Miyazono K, Heldin CH. BMP signaling is a therapeutic target in ovarian cancer. Cell Death Discov. 2020;6(1):139.

81. Li L, Tang P, Li S, Qin X, Yang H, Wu C, Liu Y. Notch signaling pathway networks in cancer metastasis: a new target for cancer therapy. Med Oncol. 2017;34(10):180.

82. Taniguchi K, Karin M. NF-kappaB, inflammation, immunity and cancer: coming of age. Nat Rev Immunol. 2018;18(5):309-24.

83. Takahashi Y, Sawada G, Kurashige J, Uchi R, Matsumura T, Ueo H, Takano Y, Eguchi H, Sudo T, Sugimachi K, et al. Amplification of PVT-1 is involved in poor prognosis via apoptosis inhibition in colorectal cancers. Br J Cancer. 2014;1 10(1):164-71.

84. Guan Y, Kuo WL, Stilwell JL, Takano H, Lapuk AV, Fridlyand J, Mao JH, Yu M, Miller MA, Santos JL, et al. Amplification of PVT1 contributes to the pathophysiology of ovarian and breast cancer. Clin Cancer Res. 2007;13(19):5745-55.

85. Ding C, Yang Z, Lv Z, Du C, Xiao H, Peng C, Cheng S, Xie H, Zhou L, Wu J, et al. Long non-coding RNA PVT1 is associated with tumor progression and predicts recurrence in hepatocellular carcinoma patients. Oncol Lett. 2015;9(2):955-63.

86. Ma Y, Wang P, Xue Y, Qu C, Zheng J, Liu X, Ma J, Liu Y. PVT1 affects growth of glioma microvascular endothelial cells by negatively regulating miR-186. Tumour Biol. 2017;39(3):1010428317694326.

87. Zhang Y, Yang G, Luo Y. Long non-coding RNA PVT1 promotes glioma cell proliferation and invasion by targeting miR-200a. Exp Ther Med. 2019;17(2):1337-45
88. Han Y, Li X, He F, Yan J, Ma C, Zheng X, Zhang J, Zhang D, Meng C, Zhang Z, et al. Knockdown of IncRNA PVT1 inhibits glioma progression by regulating miR-424 expression. Oncol Res. 2019;27(6):681-90.

89. Shao Y, Chen HT, Ma QR, Zhang YW, He YQ, Liu J. Long non-coding RNA PVT1 regulates glioma proliferation, invasion, and aerobic glycolysis via miR-140-5p. Eur Rev Med Pharmacol Sci. 2020;24(1):274-83.

90. Xue W, Chen J, Liu X, Gong W, Zheng J, Guo X, Liu Y, Liu L, Ma J, Wang P, et al. (2018) PVT1 regulates the malignant behaviors of human glioma cells by targeting miR-190a-5p and miR-488-3p. Biochim Biophys Acta Mol Basis Dis. 1864;5 Pt A:1783-94.

91. Fu C, Li D, Zhang X, Liu N, Chi G, Jin X. LncRNA PVT1 facilitates tumorigenesis and progression of glioma via regulation of MiR128-3p/GREM1 axis and BMP signaling pathway. Neurotherapeutics. 2018;15(4):1139-57.

92. Wang P, LiU YH, Yao YL, Li Z, Li ZQ, Ma J, Xue YX. Long non-coding RNA CASC2 suppresses malignancy in human gliomas by miR-21. Cell Signal. 2015;27(2):275-82.

93. Feng LL, Shen FR, Zhou JH, Chen YG. Expression of the IncRNA ZFAS1 in cervical cancer and its correlation with prognosis and chemosensitivity. Gene. 2019;696:105-12.

94. Li X, Luo Y, Liu L, Cui S, Chen W, Zeng A, Shi Y, Luo L. The long noncoding RNA ZFAS1 promotes the progression of glioma by regulating the miR-150-5p/PLP2 axis. J Cell Physiol. 2020;235(3):2937-46.

95. Yang G, Han B, Feng T. ZFAS1 knockdown inhibits viability and enhances cisplatin cytotoxicity by up-regulating miR-432-5p in glioma cells. Basic Clin Pharmacol Toxicol. 2019;125(6):518-26.

96. Gao K, Ji Z, She K, Yang Q, Shao L. Long non-coding RNA ZFAS1 is an unfavourable prognostic factor and promotes glioma cell progression by activation of the Notch signaling pathway. Biomed Pharmacother. 2017;87:555-60.

97. Xu D, Yu J, Gao G, Lu G, Zhang Y, Ma P. LncRNA DANCR functions as a competing endogenous RNA to regulate RAB1A expression by sponging miR-634 in glioma. Biosci Rep. 2018;38(1):1-9.

98. Godlewski J, Nowicki MO, Bronisz A, Williams S, Otsuki A, Nuovo G, Raychaudhury A, Newton HB, Chiocca EA, Lawler S. Targeting of the Bmi-1 oncogene/stem cell renewal factor by microRNA-128 inhibits glioma proliferation and self-renewal. Cancer Res. 2008;68(22):9125-30.

99. Feng L, Lin T, Che H, Wang X. Long noncoding RNA DANCR knockdown inhibits proliferation, migration and invasion of glioma by regulating miR-135a-5p/BMI1. Cancer Cell Int. 2020;20:53.

100. Yang BY, Meng Q, Sun Y, Gao L, Yang JX. Long non-coding RNA SNHG16 contributes to glioma malignancy by competitively binding miR20a-5p with E2F1. J Biol Regul Homeost Agents. 2018;32(2):251-61.

101. Zheng J, Liu X, Wang P, Xue Y, Ma J, Qu C, Liu Y. CRNDE promotes malignant progression of glioma by attenuating miR-384/PIWIL4/STAT3 Axis. Mol Ther. 2016;24(7):1199-215.

102. Zheng J, Li XD, Wang P, Liu XB, Xue YX, Hu Y, Li Z, Li ZQ, Wang ZH, Liu $Y H$. CRNDE affects the malignant biological characteristics of human glioma stem cells by negatively regulating miR-186. Oncotarget. 2015;6(28):25339-55.

103. Zhang K, Sun X, Zhou X, Han L, Chen L, Shi Z, Zhang A, Ye M, Wang Q, Liu C, et al. Long non-coding RNA HOTAIR promotes glioblastoma cell cycle progression in an EZH2 dependent manner. Oncotarget. 2015;6(1):537-46.

104. Ma X, Li Z, LiT, Zhu L, Li Z, Tian N. Long non-coding RNA HOTAIR enhances angiogenesis by induction of VEGFA expression in glioma cells and transmission to endothelial cells via glioma cell derived-extracellular vesicles. Am J Transl Res. 2017;9(11):5012-21.

105. Liu L, Cui S, Wan T, Li X, Tian W, Zhang R, Luo L, Shi Y. Long noncoding RNA HOTAIR acts as a competing endogenous RNA to promote glioma progression by sponging miR-126-5p. J Cell Physiol. 2018;233(9):6822-31.

106. Wang G, Li Z, Tian N, Han L, Fu Y, Guo Z, Tian Y. miR-148b-3p inhibits malignant biological behaviors of human glioma cells induced by high HOTAIR expression. Oncol Lett. 2016;12(2):879-86.

107. Bian EB, Ma CC, He XJ, Wang C, Zong G, Wang HL, Zhao B. Epigenetic modification of miR-141 regulates SKA2 by an endogenous "sponge" HOTAIR in glioma. Oncotarget. 2016;7(21):30610-25.

108. Sa L, Li Y, Zhao L, Liu Y, Wang P, Liu L, Li Z, Ma J, Cai H, Xue Y. The Role of HOTAIR/miR-148b-3p/USF1 on Regulating the Permeability of BTB. Front Mol Neurosci. 2017;10:194. 
109. Pastori C, Kapranov P, Penas C, Peschansky V, Volmar CH, Sarkaria JN, Bregy A, Komotar R, St Laurent G, Ayad NG, et al. The Bromodomain protein BRD4 controls HOTAIR, a long noncoding RNA essential for glioblastoma proliferation. Proc Natl Acad Sci USA. 2015;112(27):8326-31.

110. Chen L, Wang Y, He J, Zhang C, Chen J, Shi D. Long non-coding RNA H19 promotes proliferation and invasion in human glioma cells by downregulating miR-152. Oncol Res. 2018;26:1-10.

111. Zhao H, Peng R, Liu Q, Liu D, Du P, Yuan J, Peng G, Liao Y. The IncRNA H19 interacts with miR-140 to modulate glioma growth by targeting iASPP. Arch Biochem Biophys. 2016;610:1-7.

112. Zhang T, Wang YR, Zeng F, Cao HY, Zhou HD, Wang YJ. LncRNA H19 is overexpressed in glioma tissue, is negatively associated with patient survival, and promotes tumor growth through its derivative miR-675. Eur Rev Med Pharmacol Sci. 2016;20(23):4891-7.

113. Li C, Lei B, Huang S, Zheng M, Liu Z, Li Z, Deng Y. H19 derived microRNA-675 regulates cell proliferation and migration through CDK6 in glioma. Am J TransI Res. 2015;7(10):1747-64.

114. Jia P, Cai H, Liu X, Chen J, Ma J, Wang P, Liu Y, Zheng J, Xue Y. Long non-coding RNA H19 regulates glioma angiogenesis and the biological behavior of glioma-associated endothelial cells by inhibiting microRNA29a. Cancer Lett. 2016;381(2):359-69.

115. Liu ZZ, Tian YF, Wu H, Ouyang SY, Kuang WL. LncRNA H19 promotes glioma angiogenesis through miR-138/HIF-1alpha/NEGF axis. Neoplasma. 2020;67(1):111-8.

116. Hu Q, Yin J, Zeng A, Jin X, Zhang Z, Yan W, You Y. H19 functions as a competing endogenous RNA to regulate EMT by sponging miR130a-3p in Glioma. Cell Physiol Biochem. 2018;50(1):233-45.

117. Duan S, Li M, Wang Z, Wang L, Liu Y. H1 9 induced by oxidative stress confers temozolomide resistance in human glioma cells via activating NF-kappaB signaling. Onco Targets Ther. 2018;11:6395-404.

118. Cheng Z, Li Z, Ma K, Li X, Tian N, Duan J, Xiao X, Wang Y. Long noncoding RNA XIST smiR-429. J Cancer. 2017;8(19):4106-16.

119. Du P, Zhao H, Peng R, Liu Q, Yuan J, Peng G, Liao Y. LncRNA-XIST interacts with miR-29c to modulate the chemoresistance of glioma cell to TMZ through DNA mismatch repair pathway. Biosci Rep. 2017;37(5):1-12

120. Wang Z, Yuan J, Li L, Yang Y, Xu X, Wang Y. Long non-coding RNA XIST exerts oncogenic functions in human glioma by targeting miR-137. Am J Transl Res. 2017;9(4):1845-55.

121. Yu H, Xue Y, Wang P, Liu X, Ma J, Zheng J, Li Z, Li Z, Cai H, Liu Y. Knockdown of long non-coding RNA XIST increases blood-tumor barrier permeability and inhibits glioma angiogenesis by targeting miR-137. Oncogenesis. 2017;6(3):e303.

122. Yao Y, Ma J, Xue Y, Wang P, Li Z, Liu J, Chen L, Xi Z, Teng H, Wang Z, et al. Knockdown of long non-coding RNA XIST exerts tumor-suppressive functions in human glioblastoma stem cells by up-regulating miR-152. Cancer Lett. 2015;359(1):75-86.

123. Zhen L, Yun-Hui L, Hong-Yu D, Jun M, Yi-Long Y. Long noncoding RNA NEAT1 promotes glioma pathogenesis by regulating miR-449b-5p/cMet axis. Tumour Biol. 2016;37(1):673-83.

124. Gong W, Zheng J, Liu X, Ma J, Liu Y, Xue Y. Knockdown of NEAT1 restrained the malignant progression of glioma stem cells by activating microRNA let-7e. Oncotarget. 2016;7(38):62208-23.

125. Zhou K, Zhang C, Yao H, Zhang X, Zhou Y, Che Y, Huang Y. Knockdown of long non-coding RNA NEAT1 inhibits glioma cell migration and invasion via modulation of SOX2 targeted by miR-132. Mol Cancer. 2018:17(1):105.

126. Zhen Y, Nan Y, Guo S, Zhang L, Li G, Yue S, Liu X. Knockdown of NEAT1 repressed the malignant progression of glioma through sponging miR107 and inhibiting CDK14. J Cell Physiol. 2019;234(7):10671-9.

127. Yang $X$, Xiao Z, Du X, Huang L, Du G. Silencing of the long non-coding RNA NEAT1 suppresses glioma stem-like properties through modulation of the miR-107/CDK6 pathway. Oncol Rep. 2017;37(1):555-62.

128. Guo J, Cai H, Zheng J, Liu X, Liu Y, Ma J, Que Z, Gong W, Gao Y, Tao $W$, et al. Long non-coding RNA NEAT1 regulates permeability of the blood-tumor barrier via miR-181 d-5p-mediated expression changes in ZO-1, occludin, and claudin-5. Biochim Biophys Acta Mol Basis Dis. 2017;1863(9):2240-54.

129. Liao K, Lin Y, Gao W, Xiao Z, Medina R, Dmitriev P, Cui J, Zhuang Z, Zhao X, Qiu Y, et al. Blocking IncRNA MALAT1/miR-199a/ZHX1 axis inhibits glioblastoma proliferation and progression. Mol Ther Nucleic Acids. 2019;18:388-99.

130. Xiong Z, Wang L, Wang Q, Yuan Y. LncRNA MALAT1/miR-129 axis promotes glioma tumorigenesis by targeting SOX2. J Cell Mol Med. 2018:22:1-12

131. Li Z, Xu C, Ding B, Gao M, Wei X, Ji N. Long non-coding RNA MALAT1 promotes proliferation and suppresses apoptosis of glioma cells through derepressing Rap1B by sponging miR-101. J Neurooncol. 2017;134(1):19-28.

132. Fu Z, Luo W, Wang J, Peng T, Sun G, Shi J, Li Z, Zhang B. Malat1 activates autophagy and promotes cell proliferation by sponging miR-101 and upregulating STMN1, RAB5A and ATG4D expression in glioma. Biochem Biophys Res Commun. 2017:492(3):480-6.

133. Cai T, Liu Y, Xiao J. Long noncoding RNA MALAT1 knockdown reverses chemoresistance to temozolomide via promoting microRNA-101 in glioblastoma. Cancer Med. 2018;7(4):1404-15.

134. Chen W, Xu XK, Li JL, Kong KK, Li H, Chen C, He J, Wang F, Li P, Ge XS, et al. MALAT1 is a prognostic factor in glioblastoma multiforme and induces chemoresistance to temozolomide through suppressing miR-203 and promoting thymidylate synthase expression. Oncotarget. 2017:8(14):22783-99.

135. Cao S, Wang Y, Li J, Lv M, Niu H, Tian Y. Tumor-suppressive function of long noncoding RNA MALAT1 in glioma cells by suppressing miR-155 expression and activating FBXW7 function. Am J Cancer Res. 2016:6(11):2561-74

136. Zhu J, Gu W, Yu C. MATN1-AS1 promotes glioma progression by functioning as ceRNA of miR-200b/c/429 to regulate CHD1 expression. Cell Prolif. 2020;53(1):e12700.

137. Ding J, Zhang L, Chen S, Cao H, Xu C, Wang X. IncRNA CCAT2 enhanced resistance of glioma cells against chemodrugs by disturbing the normal function of miR-424. Onco Targets Ther. 2020;13:1431-45.

138. Kawai T, Akira S. The role of pattern-recognition receptors in innate immunity: update on Toll-like receptors. Nat Immunol. 2010;11(5):373-84.

139. Sonkoly E, Stahle M, Pivarcsi A. MicroRNAs: novel regulators in skin inflammation. Clin Exp Dermatol. 2008:33(3):312-5.

140. Primo MN, Bak RO, Schibler B, Mikkelsen JG. Regulation of pro-inflammatory cytokines TNFalpha and IL24 by microRNA-203 in primary keratinocytes. Cytokine. 2012;60(3):741-8.

141. Witwer KW, Sisk JM, Gama L, Clements JE. MicroRNA regulation of IFNbeta protein expression: rapid and sensitive modulation of the innate immune response. J Immunol. 2010:184(5):2369-76.

142. Kroesen BJ, Teteloshvili N, Smigielska-Czepiel K, Brouwer E, Boots AM, van den Berg A, Kluiver J. Immuno-miRs: critical regulators of T-cell development, function and ageing. Immunology. 2015;144(1):1-10.

143. Geng H, Tan XD. Functional diversity of long non-coding RNAs in immune regulation. Genes Dis. 2016;3(1):72-81.

144. Heerboth S, Lapinska K, Snyder N, Leary M, Rollinson S, Sarkar S. Use of epigenetic drugs in disease: an overview. Genet Epigenet. 2014;6:9-19.

145. Yu WD, Wang H, He QF, XuY, Wang XC. Long noncoding RNAs in cancerimmunity cycle. J Cell Physiol. 2018;233(9):6518-23.

146. Xu Z, Li P, Fan L, Wu M. The potential role of circRNA in tumor immunity regulation and immunotherapy. Front Immunol. 2018:9:9.

147. Wang W, Zhao Z, Yang F, Wang H, Wu F, Liang T, Yan X, Li J, Lan Q, Wang $J$, et al. An immune-related IncRNA signature for patients with anaplastic gliomas. J Neurooncol. 2018;136(2):263-71.

148. Xia P, Li Q, Wu G, Huang Y. An immune-related IncRNA signature to predict survival in glioma patients. Cell Mol Neurobiol. 2020:41:1-11.

149. Li X, Meng Y. Survival analysis of immune-related IncRNA in low-grade glioma. BMC Cancer. 2019;19(1):813.

150. Boselli M, Lee BH, Robert J, Prado MA, Min SW, Cheng C, Silva MC, Seong C, Elsasser S, Hatle KM, et al. An inhibitor of the proteasomal deubiquitinating enzyme USP14 induces tau elimination in cultured neurons. J Biol Chem. 2017:292(47):19209-25.

151. Zhou M, Zhang Z, Zhao H, Bao S, Cheng L, Sun J. An immune-related six-IncRNA signature to improve prognosis prediction of glioblastoma multiforme. Mol Neurobiol. 2018;55(5):3684-97.

152. Liang Q, Li X, Guan G, Xu X, Chen C, Cheng P, Cheng W, Wu A. Long non-coding RNA, HOTAIRM1, promotes glioma malignancy by forming a ceRNA network. Aging (Albany NY). 2019;11(17):6805-38. 
153. Tkach $M$, Thery $C$. Communication by extracellular vesicles: where we are and where we need to go. Cell. 2016;164(6):1226-32.

154. Zhao W, Liu Y, Zhang C, Duan C. Multiple roles of exosomal long noncoding RNAs in cancers. Biomed Res Int. 2019;2019:1460572.

155. Dragomir M, Chen B, Calin GA. Exosomal IncRNAs as new players in cellto-cell communication. Transl Cancer Res. 2018;7(Suppl 2):S243-52.

156. Peinado H, Aleckovic M, Lavotshkin S, Matei I, Costa-Silva B, MorenoBueno G, Hergueta-Redondo M, Williams C, Garcia-Santos G, Ghajar $C$, et al. Melanoma exosomes educate bone marrow progenitor cells toward a pro-metastatic phenotype through MET. Nat Med. 2012;18(6):883-91.

157. Zhao C, Gao F, Weng S, Liu Q. Pancreatic cancer and associated exosomes. Cancer Biomark. 2017:20(4):357-67.

158. Mittelbrunn M, Sanchez-Madrid F. Intercellular communication: diverse structures for exchange of genetic information. Nat Rev Mol Cell Biol. 2012;13(5):328-35.

159. Sun Z, Yang S, Zhou Q, Wang G, Song J, Li Z, Zhang Z, Xu J, Xia K, Chang $Y$, et al. Emerging role of exosome-derived long non-coding RNAs in tumor microenvironment. Mol Cancer. 2018;17(1):82.

160. Huang X, Yuan T, Tschannen M, Sun Z, Jacob H, Du M, Liang M, Dittmar RL, Liu Y, Liang M, et al. Characterization of human plasma-derived exosomal RNAs by deep sequencing. BMC Genomics. 2013;14:319.

161. Xie Y, Dang W, Zhang S, Yue W, Yang L, Zhai X, Yan Q, Lu J. The role of exosomal noncoding RNAs in cancer. Mol Cancer. 2019;18(1):37.

162. Wang M, Zhou L, Yu F, Zhang Y, Li P, Wang K. The functional roles of exosomal long non-coding RNAs in cancer. Cell Mol Life Sci. 2019:76(11):2059-76.

163. Naderi-Meshkin H, Lai X, Amirkhah R, Vera J, Rasko JEJ, Schmitz U. Exosomal IncRNAs and cancer: connecting the missing links. Bioinformatics. 2019;35(2):352-60.

164. Chang S, Sun L, Feng G. SP1-mediated long noncoding RNA POU3F3 accelerates the cervical cancer through miR-127-5p/FOXD1. Biomed Pharmacother. 2019:117:109133.

165. Lang HL, Hu GW, Chen Y, Liu Y, Tu W, Lu YM, Wu L, Xu GH. Glioma cells promote angiogenesis through the release of exosomes containing long non-coding RNA POU3F3. Eur Rev Med Pharmacol Sci. 2017;21(5):959-72.

166. Gao F, Feng J, Yao H, Li Y, Xi J, Yang J. LncRNA SBF2-AS1 promotes the progression of cervical cancer by regulating miR-361-5p/FOXM1 axis. Artif Cells Nanomed Biotechnol. 2019;47(1):776-82.

167. Zhang YT, Li BP, Zhang B, Ma P, Wu QL, Ming L, Xie LM. LncRNA SBF2AS1 promotes hepatocellular carcinoma metastasis by regulating EMT and predicts unfavorable prognosis. Eur Rev Med Pharmacol Sci. 2018;22(19):6333-41.

168. Zhang Z, Yin J, Lu C, Wei Y, Zeng A, You Y. Exosomal transfer of long noncoding RNA SBF2-AS1 enhances chemoresistance to temozolomide in glioblastoma. J Exp Clin Cancer Res. 2019;38(1):166.

169. Lang HL, Hu GW, Zhang B, Kuang W, Chen Y, Wu L, Xu GH. Glioma cells enhance angiogenesis and inhibit endothelial cell apoptosis through the release of exosomes that contain long non-coding RNA CCAT2. Oncol Rep. 2017;38(2):785-98.

170. Fu XM, Guo W, Li N, Liu HZ, Liu J, Qiu SQ, Zhang Q, Wang LC, Li $F, L i C L$. The expression and function of long noncoding RNA IncRNA-ATB in papillary thyroid cancer. Eur Rev Med Pharmacol Sci. 2017:21(14):3239-46.

171. Bian EB, Chen EF, Xu YD, Yang ZH, Tang F, Ma CC, Wang HL, Zhao B. Exosomal IncRNAATB activates astrocytes that promote glioma cell invasion. Int J Oncol. 2019;54(2):713-21.
172. Yang S, Lim KH, Kim SH, Joo JY. Molecular landscape of long noncoding RNAs in brain disorders. Mol Psychiatry. 2021;26(4):1060-74.

173. Liang Y, Huang S, Qiao L, Peng X, Li C, Lin K, Xie G, Li J, Lin L, Yin Y, et al. Characterization of protein, long noncoding RNA and microRNA signatures in extracellular vesicles derived from resting and degranulated mast cells. J Extracell Vesicles. 2020;9(1):1697583.

174. O'Brien K, Breyne K, Ughetto S, Laurent LC, Breakefield XO. RNA delivery by extracellular vesicles in mammalian cells and its applications. Nat Rev Mol Cell Biol. 2020;21(10):585-606.

175. Wang W, Han Y, Jo HA, Lee J, Song YS. Non-coding RNAs shuttled via exosomes reshape the hypoxic tumor microenvironment. J Hematol Oncol. 2020;13(1):67.

176. Ma P, Pan Y, LiW, Sun C, Liu J, Xu T, Shu Y. Extracellular vesicles-mediated noncoding RNAs transfer in cancer. J Hematol Oncol. 2017;10(1):57.

177. Zhang WL, Liu Y, Jiang J, Tang YJ, Tang YL, Liang XH. Extracellular vesicle long non-coding RNA-mediated crosstalk in the tumor microenvironment: Tiny molecules, huge roles. Cancer Sci. 2020;111(8):2726-35.

178. Born LJ, Harmon JW, Jay SM. Therapeutic potential of extracellular vesicle-associated long noncoding RNA. Bioeng Transl Med. 2020;5(3):e10172.

179. Sahoo S, Adamiak M, Mathiyalagan P, Kenneweg F, Kafert-Kasting $\mathrm{S}$, Thum T. Therapeutic and diagnostic translation of extracellular vesicles in cardiovascular diseases: roadmap to the clinic. Circulation. 2021;143(14):1426-49.

180. Carlevaro-Fita J, Lanzos A, Feuerbach L, Hong C, Mas-Ponte D, Pedersen $J S$, Drivers P, Functional Interpretation G, Johnson R, Consortium P. Cancer LncRNA Census reveals evidence for deep functional conservation of long noncoding RNAs in tumorigenesis. Commun Biol. 2020;3(1):56.

181. Cecchelli R, Berezowski V, Lundquist S, Culot M, Renftel M, Dehouck MP, Fenart L. Modelling of the blood-brain barrier in drug discovery and development. Nat Rev Drug Discov. 2007:6(8):650-61.

182. Qi P, Zhou XY, Du X. Circulating long non-coding RNAs in cancer: current status and future perspectives. Mol Cancer. 2016;15(1):39.

183. Schwarzenbach $\mathrm{H}$, Hoon DS, Pantel K. Cell-free nucleic acids as biomarkers in cancer patients. Nat Rev Cancer. 2011;11(6):426-37.

184. Anfossi S, Babayan A, Pantel K, Calin GA. Clinical utility of circulating non-coding RNAs - an update. Nat Rev Clin Oncol. 2018;15(9):541-63.

185. Wang Z, Gu J, Han T, Li K. High-throughput sequencing profile of laryngeal cancers: analysis of co-expression and competing endogenous RNA networks of circular RNAs, long non-coding RNAs, and messenger RNAs. Ann Transl Med. 2021;9(6):483.

186. Arun G, Diermeier SD, Spector DL. Therapeutic targeting of long noncoding RNAs in cancer. Trends Mol Med. 2018;24(3):257-77.

187. Burrell RA, McGranahan N, Bartek J, Swanton C. The causes and consequences of genetic heterogeneity in cancer evolution. Nature. 2013;501(7467):338-45.

188. Dagogo-Jack I, Shaw AT. Tumour heterogeneity and resistance to cancer therapies. Nat Rev Clin Oncol. 2018;15(2):81-94.

189. Cheetham SW, Gruhl F, Mattick JS, Dinger ME. Long noncoding RNAs and the genetics of cancer. Br J Cancer. 2013;108(12):2419-25.

190. Battle A, Khan Z, Wang SH, Mitrano A, Ford MJ, Pritchard JK, Gilad Y. Genomic variation. Impact of regulatory variation from RNA to protein. Science. 2015;347(6222):664-7.

\section{Publisher's Note}

Springer Nature remains neutral with regard to jurisdictional claims in published maps and institutional affiliations. 